\title{
GOING MULTINATIONAL UNDER EXCHANGE RATE UNCERTAINTY
}

\author{
HENRY ARAY - UNIVERSIDAD DE GRANADA \\ JAVIER GARDEAZABAL - UNIVERSIDAD DEL PAÍS VASCO
}

\begin{abstract}
Aвstract. When an exporting firm should exercise the option to invest abroad under exchange rate uncertainty in the context of a Cournot market equilibrium is analyzed. The model shows that the degree of hysteresis in direct investment grows with the number of firms in the industry. We compute the market value of the domestic firm and foreign competitors taking into account the effect of the option held by the domestic producer. When there are sunk maintenance costs and the number of firms is close to the long run equilibrium number of firms, there may be dumping for a range of exchange rate values. Tariffs have the well known FDI-inducing effect, more so in less competitive markets, and are more effective at deterring delocation. A tariff might have the undesired effect of inducing dumping.
\end{abstract}

KeYwords: Foreign Direct Investment, Oligopoly, Real Option, Dumping.

JEL: F23, L13.

We would like to thank Luis María Abadie, Jacint Balaguer-Coll, José Manuel Campa, Santiago Carbó, José Chamorro, María Paz Espinosa, Angel León, Vicente Orts, Gonzalo Rubio, José María Usategui for their comments. Financial support from Spanish Ministry of Education and Science (grant SEJ2006-0630) and BBVA foundation is acknowledged.

Henry Aray: Departamento de Teoría e Historia Económica, Universidad de Granada, Campus Universitario de La Cartuja, E-18071 Granada, Spain. E-mail: haray@ugr.es Javier Gardeazabal: Departamento de Fundamentos del Análisis Económico II, Universidad del País Vasco, Avda. Lehendakari Aguirre 83, E-48015 Bilbao, Spain. E-mail: javier.gardeazabal@ehu.es. 


\section{INTRODUCTION}

A foreign market may be served through exports, a foreign subsidiary or licensing a foreign producer. Setting up a new plant in a foreign country (or acquiring an existing one) induces a flow of Foreign Direct Investment (FDI). International trade literature suggests that differences in production costs might affect the choice between exporting and FDI (see Wong, 1995). Differences in productivity are, according to Helpman, Melitz and Yeaple (2004), a factor determining the choice between FDI and exporting, with the most productive firms prone to FDI.

Nominal exchange rate movements may also affect FDI. It can be argued that going multinational becomes more profitable for domestic firms as the domestic currency appreciates. There are two reasons why this may be the case. First, with an appreciating domestic currency, exporting firms become less competitive in foreign markets and, hence, are more likely to go multinational. Second, the sunk cost of setting up a plant in a foreign country becomes cheaper, the more appreciated the domestic currency is. Symmetrically, setting up a plant in the domestic economy will be more attractive for foreign firms as the domestic currency depreciates. Therefore, intuitively at least, exchange rate fluctuations may trigger FDI flows.

Most flows of FDI take place between industrial economies whose exchange rates float freely. This observation has given rise to an interesting field in international economics which explores the relationship between exchange rates and FDI. This literature includes several lines of research. Theoretical models such as Goldberg and Kolstad (1995) and Sung and Lapan (2000) show that exchange rate movements influence the location decisions of firms. On the other hand, Darby, Hallett, Ireland and Piscitelly (1999) study the effect of exchange rate variability on the degree of hysteresis in FDI flows. Campa, Donnenfeld and Weber (1998) study the effect of strategic interaction between domestic and foreign firms on FDI. Shrikhande (2002) and Russ (2007) show how FDI and exchange rates are jointly determined in general equilibrium models. The empirical evidence on the relationship between exchange rate fluctuations and FDI includes Blonigen (1997), who argues that the exchange rate may affect FDI as acquisitions involve firm-specific assets which can generate returns in domestic currency. Campa (1993) finds a negative effect of exchange rate volatility on the number of foreign firms entering the U.S. market. Exchange rates have been found to be a determinant of FDI flows for groups of countries. Xing and Wan (2006) and Gottschalk and Hall (2008) 
document the importance of exchange rates for FDI inflows in developing countries (China, Indonesia, Malaysia, the Philippines and Thailand) and Brouwer, Paap and Viaene (2008) for the 2004 EU enlargement countries (Cyprus, Czech Republic, Estonia, Hungary, Latvia, Lithuania, Malta, Poland, Slovakia and Slovenia). The link between FDI and exchange rates also includes firm-level evidence as reported by Buch and Kleinert (2008) for the case of Germany and sectoral evidence as shown by Xing (2006) for China.

We analyze the choice between exporting and FDI from a real option perspective. Orthodox investment theory suggests that a firm should incur FDI expense when the net present value of the investment in a foreign country is positive. The option theory of investment recognizes that uncertainty may induce firms to wait for more favorable conditions. The arrival of new information might affect the timing of the investment. On the other hand, FDI is costly and at least partly irreversible. Hence, the possibility of delay and irreversibility are two very important features of the investment that firms take into account before undertaking an FDI project. A firm facing this problem can be understood as having a financial option where the firm has the right to buy an asset -the plant in a foreign country- at any future time. The price that the firm has to pay in order to exercise the option -the strike price- is the sunk cost of the investment. Once the firm has decided to undertake an FDI expense, the firm has the option to revert to the initial situation by withdrawing from the foreign country, thus incurring another sunk cost.

The theoretical framework for dealing with this investment problem was developed by Dixit (1989a, 1989b) and Dixit and Pindyck (1994), building on previous work by McDonald and Siegel (1986). Originally, the option theory of investment dealt with market equilibria with no strategic competition, i.e. perfect competition and monopoly. More recently, this literature has been extended to the case of strategic competition in investment option exercising (Trigeorgis (1996), Grenadier (2002), Smit and Trigeorgis (2004) and Novy-Marx (2007)) and to product market duopolistic competition by Paxson and Pinto (2005). This paper analyzes FDI using the option theory of investment when firms engage in strategic competition in the product market.

Then, we briefly describe the way we proceed and how we contribute to the literature. First, we set up a model of a domestic producer who serves a foreign market through exports and has the option to set up a plant in the foreign country. This decision is crucially affected 
by the time evolution of the nominal exchange rate. Using real option pricing techniques we compute the value of the option held by the domestic firm and the market value of the firm. By doing so we are able to determine the exchange rate values that trigger FDI flows. As is usual in investment problems, the solution exhibits some degree of hysteresis, that is, certain movements of the exchange rate trigger FDI flows while their reversal do not. The model explains how hysteresis depends on the number of firms in the market.

Second, in addition to computing the value of the option holder firm, we also value foreign firms. We show how even though foreign competitors are not endowed with the option to invest (they are already in the market), the fact that the domestic firm has the option to invest abroad affects the market value of foreign competitors.

Third, we show that while the domestic firm retains the option to invest abroad, dumping can appear. This type of dumping is of the same nature as described by Sercu and Vanhulle (1992). In their model, an exporter has the option to close down the plant or continue exporting. When re-entry into the exporting market entails a sunk cost, the exporter may optimally decide to suffer a loss temporarily. In our model, the exporter has the option to go multinational and may optimally decide to export at a loss while waiting for more favorable conditions to install a plant in the foreign country. However, in our model the option to invest abroad precludes dumping in cases where it would appear in case the only alternative to exporting was shouting down business.

Fourth, we further extend our model to considering the effect of tariffs levied on foreign consumers' imports. In this scenario, the well known tariff-jumping FDI result due to Motta (1992) is obtained. That is, a tariff may induce the domestic producer to install capacity in the foreign country rather than continue exporting. Our analysis shows that tariffs are more effective at deterring delocation than inducing FDI. More surprisingly, the introduction of a tariff (or the increase of an existing one) may induce dumping.

The rest of the article is organized as follows. Section 2 describes the market equilibrium when the domestic firm is exporting and when it goes multinational and the optimal timing rule for undertaking a foreign project. Section 3 shows the numerical solution of the model for a baseline parameterization. Section 4 studies the relationship between exporting, FDI and dumping. Section 5 considers the effects of tariffs. Section 6 presents robustness exercises. Finally, Section 7, summarizes our main findings. 


\section{The Model}

We consider a market located in a foreign country where one domestic firm and $N-1$ foreign firms sell their entire production of a homogeneous good competing à la Cournot. The number of firms, $N$, is fixed and exogenously given, i.e. there is no entry or exit of firms. The domestic firm initially exports to the foreign country and we say the firm is in state $j=0$. The firm may set up a plant in the foreign country, thus becoming multinational, and the firm is then said to be in state $j=1$. By setting up a plant in the foreign market, the domestic firm incurs in greenfield FDI. 1

The domestic and foreign countries have different currencies. Let $S$ be the exchange rate, defined as the number of domestic currency units necessary to buy one unit of foreign currency.

Let the foreign currency market price in state $j, p_{j}$ be given by the inverse demand function

$$
p_{j}=\alpha-\beta Q_{j}
$$

where $\alpha$ and $\beta$ are positive parameters, $Q_{j}=q_{j}+\sum_{i=1}^{N-1} q_{i j}^{*}$ is the total quantity of the good supplied in state $j, q_{j}$ is the quantity produced by the domestic firm in state $j$ and $q_{i j}^{*}$ is the quantity produced by foreign firm $i$ in state $j$.

Production costs in the domestic country are denominated in domestic currency while production costs and sales in the foreign country are denominated in foreign currency. In state $j=0$, when the domestic firm exports, the domestic currency cost of producing $q_{0}$ units is assumed to be linear

$$
C\left(q_{0}\right)=\phi+\gamma q_{0}
$$

where $\phi$ is a sunk cost and $\gamma$ is a constant marginal cost. The sunk cost $\phi$ refers to a maintenance expenditure or advertising expenditure necessary to retain brand awareness and is independent of the level of output. In state $j=1$, when the domestic firm has gone multinational, the foreign currency cost of producing $q_{1}$ units is

$$
C^{*}\left(q_{1}\right)=\phi^{*}+\gamma^{*} q_{1} .
$$

In both states, foreign firms face a foreign currency cost function

$$
C^{*}\left(q_{i j}^{*}\right)=\phi^{*}+\gamma^{*} q_{i j}^{*}
$$

\footnotetext{
${ }^{1}$ Our model embodies the monopoly as a special case when there is one exporting firm and the number of foreign firms is zero, the duopoly with one foreign firm, the triopoly with two foreign firms, and so on. This model is very easily extended to the case of $M$ domestic firms and $N$ foreign firms. However, if all domestic firms are identical the choice between exporting and going multinational is the same for all domestic firms.
} 
The domestic firm initially exports to the foreign market. At each point in time, the domestic and foreign firms decide how much to produce given the exchange rate. In addition, the domestic firm has to decide whether to continue exporting or to become multinational by setting up a plant in the foreign economy and closing down the domestic plant incurring an exogenous sunk cost of $I$ units of foreign currency. If the domestic firm becomes multinational, it has to decide whether to continue serving the foreign market through its foreign subsidiary or delocate from the foreign economy, closing down the foreign plant and reopening its domestic plant incurring another sunk cost of $L$ units of foreign currency, and serve the foreign market through exports.

Before solving the model, we discuss some implicit assumptions of our setup. First and for simplicity, our model does not consider the existence of capacity limits. In fact, the role of capacity limits has already been studied within a very similar framework. Rob and Vettas (2003) lay out a model of a monopoly with a capacity limit and demand uncertainty where the optimal mode of operation is to combine production in both plants, i.e. to combine FDI and exports. In their model, the domestic capacity restriction is solved by setting up capacity abroad. In our model, however, given the assumptions of constant marginal cost and no capacity restrictions, the domestic firm optimally chooses to produce all its output in one location. Our work and Rob and Vettas (2003) could be considered complementary as we do not consider the existence of capacity limits but allow for product market strategic interaction whereas they allow for capacity constraints, but limit their analysis to the monopoly case with no strategic interaction among firms. Relaxing the assumption of no capacity limit would imply that firms had the option to invest in capacity as in Levitan and Shubik (1972), Kreps and Scheinkman (1983) and Moreno and Ubeda (2005). Poddar and Sasaki (2002) show that such capacity choices can be used as entry barriers. This is an interesting extension of our model, however, allowing for simultaneous strategic choices in capacity investment and production would render a much more complicated model. Instead, we have used a simpler route by setting exogenous entry barriers in the form of exogenous sunk costs of setting up a plant in the foreign economy and delocating from the foreign economy and reopening the domestic plant.

Second, we analyze the case where the domestic and foreign firms play the one-shot Cournot equilibrium strategies in every period and do not explore collusive equilibria. This again is 
another interesting extension of our model. However, there should be a multiplicity of such collusive equilibria and, therefore, there is no clear way to proceed in this direction.

Third and also with the aim of simplifying the analysis, our model does not consider the existence of inventories. Levitan and Shubik (1972) show that firms can use inventories to avoid short-term effects of capacity limits. Rotemberg and Saloner (1989) show that in a duopoly, inventories can be used to punish deviations from a collusive equilibrium. Since we consider neither capacity limits nor collusion, it makes sense not to complicate the model by introducing inventories. Another good reason for ignoring inventories is that according to Thille (2006), in the context of a Cournot duopoly and without depreciation, inventories have no effect on the average level of prices.

In the next two subsections, we compute the domestic firm's operating profits under two different scenarios: first, when it exports to the foreign market, and second, when it sets up a plant in the foreign country, that is, it goes multinational.

2.1. Exporting State. At each point in time, the domestic firm solves

$$
\max _{q_{0} \geq 0} S(1-\tau)\left(\alpha-\beta Q_{0}\right) q_{0}-\phi-\gamma q_{0}
$$

where $\tau \in(-\infty, 1]$. Positive values of $\tau$ can be interpreted as iceberg-type transport costs or ad-valorem tariffs and negative values as export subsidies.

A typical foreign firm solves

$$
\max _{q_{i 0}^{*} \geq 0}\left(\alpha-\beta Q_{0}\right) q_{i 0}^{*}-\phi^{*}-\gamma^{*} q_{i 0}^{*} .
$$

Since all foreign firms have identical cost functions, they will all produce exactly the same quantity, say $q_{i 0}^{*}$. The total quantity sold in the foreign market is $Q_{0}=q_{0}+(N-1) q_{i 0}^{*}$. Section A.1 of the Appendix shows that the outputs of the domestic firm and a foreign firm in the Cournot equilibrium are

$$
\begin{gathered}
q_{0}=\frac{S(1-\tau)\left(\alpha+(N-1) \gamma^{*}\right)-N \gamma}{\beta(N+1) S(1-\tau)}, \\
q_{i 0}^{*}=\frac{S(1-\tau)\left(\alpha-2 \gamma^{*}\right)+\gamma}{\beta(N+1) S(1-\tau)} .
\end{gathered}
$$

We assume that $\alpha>2 \gamma^{*}$, so that foreign firms produce positive quantities for all exchange rate values. A domestic currency depreciation increases the market share of the exporting firm and reduces that of foreign competitors. 


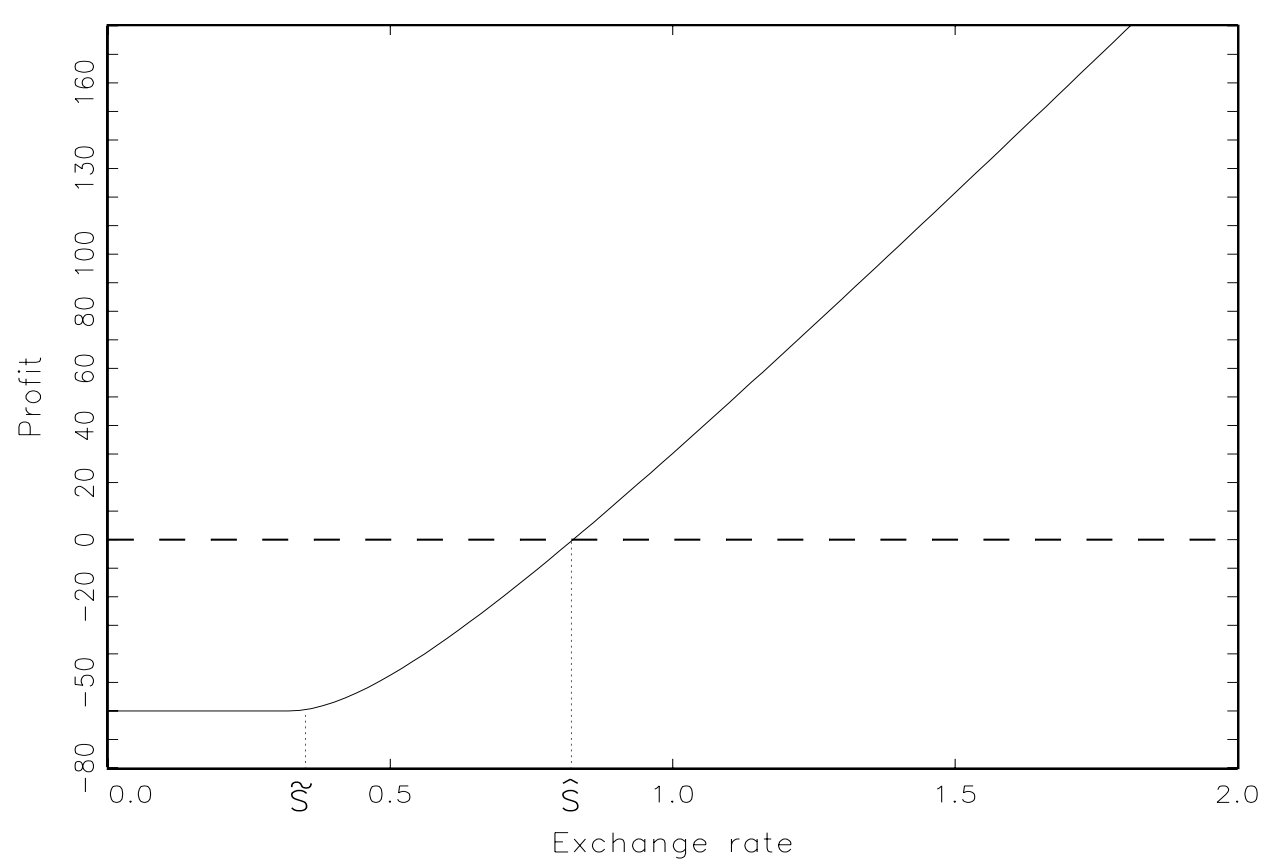

FiguRE 1. This figure shows profits as as a function of the exchange rate in the exporting state when the number of firms is $N=9$, there are no tariffs or transport costs, $\tau=0$, the inverse demand function is $p=100-Q, \gamma=\gamma^{*}=5$ and $\phi=\phi^{*}=60$.

For exchange rate values above

$$
\widetilde{S}=\frac{N \gamma}{(1-\tau)\left(\alpha+(N-1) \gamma^{*}\right)}
$$

it is optimal for the domestic firm to produce and export positive quantities while for exchange rate values below $\widetilde{S}$, its optimal production is zero.

Substituting (1)-(2) in the objective of the exporting firm yields operating profits as a function of the exchange rate

$$
\pi_{0}(S)= \begin{cases}\frac{\left[S(1-\tau)\left(\alpha+(N-1) \gamma^{*}\right)-N \gamma\right]^{2}}{\beta(N+1)^{2} S(1-\tau)}-\phi & \text { if } \quad S>\widetilde{S} \\ -\phi & \text { if } \quad S \leq \widetilde{S}\end{cases}
$$

The profit function 3 is plotted in Figure 1. There are two features of this function worth mentioning. First, for exchange rate values below $\widetilde{S}$, the optimal production is zero and profits are negative and constant at $-\phi$. The profit function in state 0 is continuous, but not differentiable at $\widetilde{S}$. This non differentiability will pose a technical problem later. Second, let $\widehat{S}$ be the only root of $\pi_{0}(S)=0$. Then, for all exchange rate values below $\widehat{S}$ the domestic 
firms loses by exporting. We show below that the exporting firm may wish to incur negative profits provided the value of the firm is positive. This occurs when the option to become multinational is positive and offsets current negative profits.

2.2. Multinational State. Suppose that the domestic firm decides to set up a plant in the foreign country and, therefore, faces the same cost function as local firms. The firm will compete as a multinational with the $N-1$ foreign firms. Even though the domestic firm has gone multinational, its headquarters in the source country maximize profits in domestic currency, that is

$$
\max _{q_{1} \geq 0} S\left[\left(\alpha-\beta Q_{1}\right) q_{1}-\phi^{*}-\gamma^{*} q_{1}\right] .
$$

Foreign firms maximize profits in foreign currency, that is

$$
\max _{q_{i 1}^{*} \geq 0}\left[\left(\alpha-\beta Q_{1}\right) q_{i 1}^{*}-\phi^{*}-\gamma^{*} q_{i 1}^{*}\right] .
$$

Section A.2 of the Appendix shows that the Cournot equilibrium production values are

$$
q_{1}=q_{11}^{*}=q_{21}^{*}=\ldots \ldots=\frac{\alpha-\gamma^{*}}{\beta(N+1)} .
$$

Notice that our previous assumption that $\alpha>2 \gamma^{*}$ guarantees positive production values regardless of the exchange rate.

Operating profits for the multinational firm are now a linear function of the exchange rate

$$
\pi_{1}(S)=S\left[\frac{1}{\beta}\left(\frac{\alpha-\gamma^{*}}{N+1}\right)^{2}-\phi^{*}\right]
$$

We assume that the number of firms in the industry is low enough to generate non negative profits of the multinational firm.

2.3. A two-period two-state model. For illustrative purposes, we first analyze a simplified two-period two-state version of the model. This simplified model illustrates how the firm might wish to defer the decision to invest abroad despite the fact that going multinational would be profitable today. In addition, this simple set up allows us to compute the value of the option to go multinational by comparing the net present value of the firm with and without the option.

The structure of the model is depicted in Table 1. Suppose that initially the domestic firm exports and the exchange rate is $S$. At the beginning of each period, the exchange rate either rises or falls in an amount of $\Delta>0$ with probability 0.5 . Once the exchange rate is known, 
Table 1: Flow diagram in a two-period two-state model

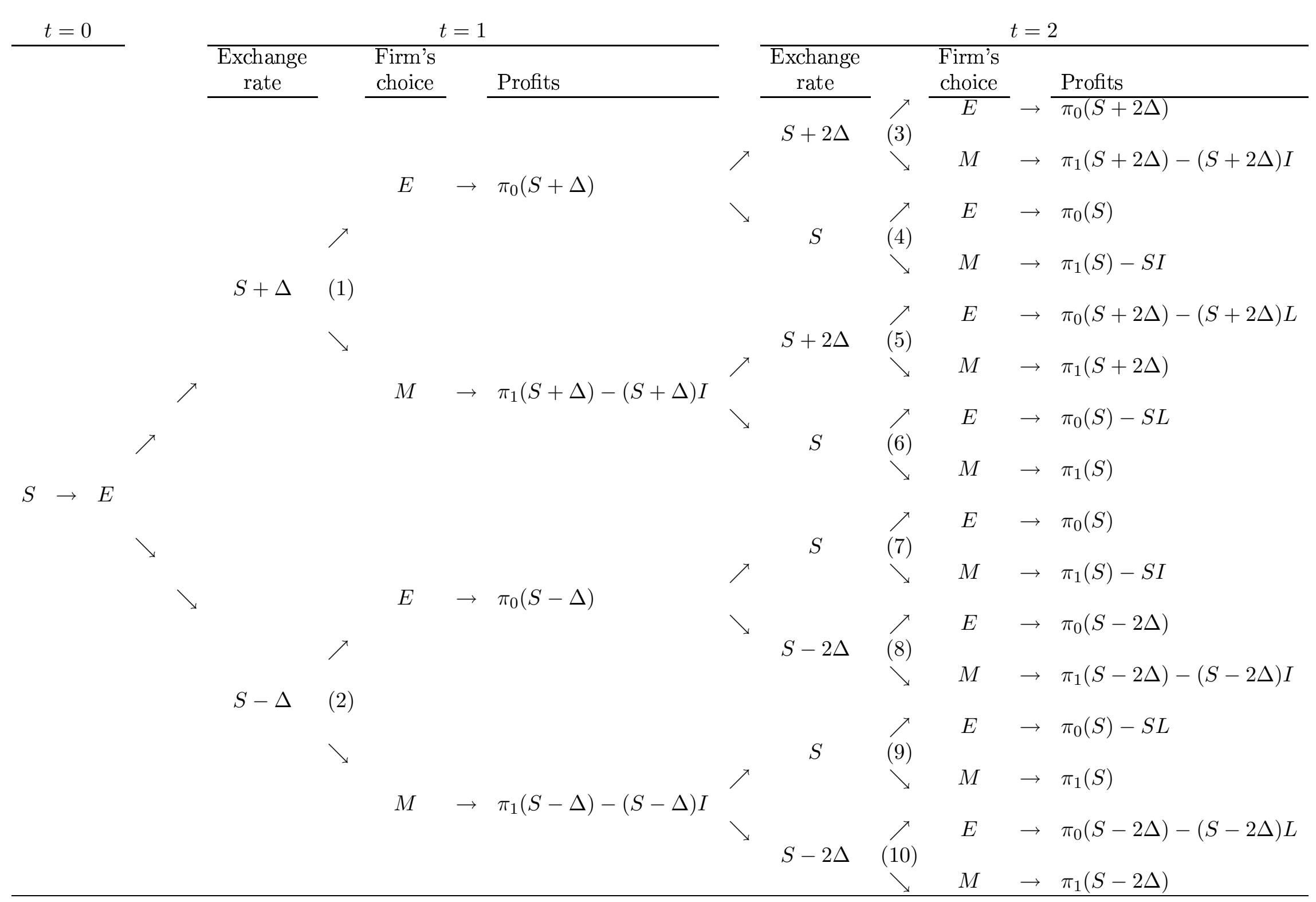


the firm decides the operation mode: either exporting $(E)$ or going multinational $(M)$. Then firms engage in quantity competition and profits are realized.

For simplicitly, suppose the initial exchange rate is $S=1, \gamma=\gamma^{*}, \phi=\phi^{*}, \tau=0$ and $I=L$. Under these circumstances, it is easy to show that $\pi_{0}(1)=\pi_{1}(1), \pi_{0}(1+\Delta)>\pi_{1}(1+\Delta)$ and $\pi_{0}(1-\Delta)<\pi_{1}(1-\Delta)$. Let us proceed by backwards induction to solve the model. In the second period, once the firm observes the exchange rate, some of the alternative modes of operation can be ruled out. The preferred strategies at each decision node are listed in Table 2. For instance, in node 3 , exporting yields $\pi_{0}(1+2 \Delta)$ while going multinational returns a lower profit $\pi_{1}(1+2 \Delta)-(1+2 \Delta) I$. In constructing Table 2 , we are assuming that after two consecutive appreciations, in node 8 , the increase in period two profits from going multinational more than compensate the sunk cost of the investing abroad. Otherwise, the option to invest abroad would never be exercised in the second period. Similarly, we assume that after two consecutive depreciations, in node 5 , the increase in period two profits from reverting to exporting more than compensate the sunk cost of delocating.

Table 2: Nodes, Strategies and Profits

\begin{tabular}{|c|c|c|c|c|}
\hline Node & \multicolumn{2}{|c|}{ Preferred alternative } & \multicolumn{2}{|c|}{ Dominated alternative } \\
\hline 3 & $E$ & $\pi_{0}(1+2 \Delta)$ & $M$ & $\pi_{1}(1+2 \Delta)-(1+2 \Delta) l$ \\
\hline 4 & $E$ & $\pi_{0}(1)$ & $M$ & $\pi_{1}(1)-I$ \\
\hline 5 & $E$ & $\pi_{0}(1+2 \Delta)-(1+2 \Delta) I$ & $M$ & $\pi_{1}(1+2 \Delta)$ \\
\hline 6 & $M$ & $\pi_{1}(1)$ & $E$ & $\pi_{0}(1)-I$ \\
\hline 7 & $E$ & $\pi_{0}(1)$ & M & $\pi_{1}(1)-I$ \\
\hline 8 & $M$ & $\pi_{1}(1-2 \Delta)-(1-2 \Delta) I$ & $E$ & $\pi_{0}(1-2 \Delta)$ \\
\hline 9 & $M$ & $\pi_{1}(1)$ & $E$ & $\pi_{0}(1)-I$ \\
\hline 10 & $M$ & $\pi_{1}(1-2 \Delta)$ & $E$ & $\pi_{0}(1-2 \Delta)-(1-2 \Delta) I$ \\
\hline
\end{tabular}

Given the second period optimal choices, the domestic firm observes that at node 1 the expected net discounted profit of exporting is greater than that of going multinational

$$
\begin{gathered}
\pi_{0}(1+\Delta)+\frac{1}{1+\rho}\left(\frac{1}{2} \pi_{0}(1+2 \Delta)+\frac{1}{2} \pi_{0}(1)\right)> \\
\pi_{1}(1+\Delta)+\frac{1}{1+\rho}\left(\frac{1}{2}\left(\pi_{0}(1+2 \Delta)-(1+2 \Delta) I\right)+\frac{1}{2} \pi_{1}(1)\right)-I .
\end{gathered}
$$


Further assume that at node 2, the net discouted profit from exporting is greater than the net profit from investing abroad, that is

$$
\begin{gathered}
\pi_{0}(1-\Delta)+\frac{1}{1+\rho}\left(\frac{1}{2} \pi_{0}(1)+\frac{1}{2}\left(\pi_{1}(1-2 \Delta)-(1-2 \Delta) I\right)\right)> \\
\pi_{1}(1-\Delta)+\frac{1}{1+\rho}\left(\frac{1}{2} \pi_{1}(1)+\frac{1}{2}\left(\pi_{1}(1-2 \Delta)\right)-I .\right.
\end{gathered}
$$

This simple two-period two-state model illustrates how uncertainty affects the equilibrium outcome and allows us to price the option to go multinational easily. At node 2, the domestic firm exports despite the fact that period 1 profits from going multinational are higher and retains the option to go multinational in period 2. If there was no uncertainty, the optimal decision would be taken in the first period, however, uncertainty about the second period exchange rate makes it optimal to delay the decision whether to go multinational.

The value of this option is easily priced in this context. We just compare the value of exporting and retaining the option to go multinational in period 2

$$
\pi_{0}(1-\Delta)+\frac{1}{1+\rho}\left(\frac{1}{2} \pi_{0}(1)+\frac{1}{2}\left(\pi_{1}(1-2 \Delta)-(1-2 \Delta) I\right)\right)
$$

with the value of exporting remaining exporting forever (with no option to invest in period 2)

$$
\pi_{0}(1-\Delta)+\frac{1}{1+\rho}\left(\frac{1}{2} \pi_{0}(1)+\frac{1}{2}\left(\pi_{0}(1-2 \Delta)\right) .\right.
$$

We find that the value of the option to be equal to the difference of the previous two equations

$$
\frac{1}{1+\rho} \frac{1}{2}\left(\pi_{1}(1-2 \Delta)-(1-2 \Delta) I-\pi_{0}(1-2 \Delta)\right) .
$$

Therefore, the value of the option will be positive when the increase in profits from going multinational in the second period $\pi_{1}(1-2 \Delta)-\pi_{0}(1-2 \Delta)$ is greater than the sunk cost of the investment $(1-2 \Delta) I$. If this condition is not satisfied, it will not be worth exercising the option.

2.4. Option pricing and optimal exercising. Let us now consider a more general set up, with continuous and infinite time and let now the exchange rate take any positive value. For the sake of simplicity we assume that the only source of uncertainty comes from exchange rate movements. Assume that the exchange rate evolves over time exogenously as a geometric Brownian motion

$$
\frac{d S}{S}=\mu d t+\sigma d z
$$


where $d z$ is the increment of a standard Wiener process. The parameter $\mu$ is the expected depreciation rate and $\sigma$ is a measure of exchange rate volatility. Therefore, we are disregarding any general equilibrium effect of the aggregate outcome of this industry on the exchange rate. In other words, the exchange rate is assumed to be exogenously given. Under this assumption the value of the domestic firm follows a stochastic process and the timing of FDI flows can be thought of as an option pricing problem.

The domestic firm decides how much to produce and sell in the foreign market and when to switch from exporting to multinational and viceversa. In state $j=0$, the firm decides whether to produce only in the home country or to stop producing domestically and set up a plant in the foreign country, which means exercising the option to go multinational. In state $j=1$ the firm decides whether to continue producing abroad or to go domestic again, which means exercising the option to reverse. A firm facing such a problem and able to change flexibly from one state to another has to price both options simultaneously.

In order to find the option price, it is necessary to value the domestic firm. This valuation is conveniently done using a risk-neutral probability measure. Appendix A.3 shows that this change of measure is easily accomplished by letting the drift in the exchange rate process $\mu$ (the expected depreciation rate) be equal to the riskless rate $r$ minus the so called "convenience yield" $\delta$.

Let $V_{j}(S)$ be the value of the firm given an initial exchange rate $S$ and state $j$ and following optimal policies thereafter. When the domestic firm exports to the foreign country, it earns a profit $\pi_{0}(S)$. In addition, the value of the firm is expected to change, yielding a capital gain of $E\left(d V_{0}(S)\right) / d t$. Under no-arbitrage opportunities, it must be the case that

$$
\frac{E\left(d V_{0}(S)\right)}{d t}+\pi_{0}(S)=r V_{0}(S)
$$

where $r$ is the risk free rate of return. We will assume that $r>\mu$, otherwise the present discounted value of the firm is unbounded. Similarly, when the firm is multinational we have

$$
\frac{E\left(d V_{1}(S)\right)}{d t}+\pi_{1}(S)=r V_{1}(S) \text {. }
$$

Appendix A.4 shows that for $S \geq \widetilde{S}$, a solution to equations (6) and (7) can be written as

$$
V_{0}(S)=A S^{\eta_{0}}+a S+b S^{-1}+c
$$

$$
V_{1}(S)=B S^{\eta_{1}}+e S
$$


where $\eta_{0}<0, \eta_{1}>1, a, b, c$ and $e$ are constants given in Appendix A.4 and $A$ and $B$ are constants to be determined.

The economic interpretation of the solution is simple. The value of the firm when exporting, $V_{0}(S)$, is the sum of two components: the expected present value of exporting, $a S+b S^{-1}+c$, plus the value of the option to go multinational, $A S^{\eta_{0}}$. Similarly, the value of the firm when multinational is the sum of two terms: the expected present value of selling in the foreign market as a multinational, $e S$, plus the value of the option to abandon the foreign country, $B S^{\eta_{1}}$. Logically, the value of the options can never become negative, so we restrict $A$ and $B$ to being non-negative. Mathematically speaking, the value of the firm in either state is the sum of the expected present value of the firm in that state plus an intrinsic bubble (a bubble that depends on fundamentals).

Let $\underline{S}$ be the threshold exchange rate low enough to induce the firm to invest in the host country, that is, the exchange rate at which the firm exercises the option to go multinational. Similarly, $\bar{S}$ is the threshold exchange rate high enough to induce the firm to reverse, that is, the exchange rate at which the multinational firm exercises the option to abandon the host country. Thus, the firm retains its option to go multinational over the interval $(\underline{S}, \infty)$. However, a multinational firm will continue operating in the host country over the interval $(0, \bar{S})$. The ratio $(\bar{S}-\underline{S}) / \underline{S}$ can be interpreted as a measure of the degree of hysteresis in FDI flows.

When the domestic firm goes multinational, it has to pay $I$ units of foreign currency to exercise that option. This is the sunk cost of closing down the plant in the domestic country and setting up a plant in the foreign country. The exchange rate that makes the domestic firm indifferent between exporting and going multinational, $\underline{S}$, must satisfy the value matching condition

$$
V_{0}(\underline{S})=V_{1}(\underline{S})-\underline{S} I .
$$

Optimal exercising also requires that the smooth pasting condition

$$
V_{0}^{\prime}(\underline{S})=V_{1}^{\prime}(\underline{S})-I
$$

be satisfied. Similarly, when a multinational firm suspends operations in the host country, it must pay a lump-sum exit cost $L$ in foreign currency to exercise that option. Thus, $L$ represents the sunk cost of closing down the plant in the foreign country and setting up a new 
plant in the domestic country. Let $\bar{S}$ be the exchange rate value that makes the multinational firm indifferent between producing abroad and going domestic again. The value matching condition is

$$
V_{1}(\bar{S})=V_{0}(\bar{S})-\bar{S} L
$$

and the smooth pasting condition is

$$
V_{1}^{\prime}(\bar{S})=V_{0}^{\prime}(\bar{S})-L
$$

Equations (10) to (13) define a nonlinear system of equations

$$
\begin{array}{r}
B \underline{S}^{\eta_{1}}-A \underline{S}^{\eta_{0}}+(e-a) \underline{S}-b \underline{S}^{-1}-c-\underline{S} I=0 \\
\eta_{1} B \underline{S}^{\eta_{1}-1}-\eta_{0} A \underline{S}^{\eta_{0}-1}+(e-a)+b \underline{S}^{-2}-I=0 \\
B \bar{S}^{\eta_{1}}-A \bar{S}^{\eta_{0}}+(e-a) \bar{S}-b \bar{S}^{-1}-c+\bar{S} L=0 \\
\eta_{1} B \bar{S}^{\eta_{1}-1}-\eta_{0} A \bar{S}^{\eta_{0}-1}+(e-a)+b \bar{S}^{-2}+L=0
\end{array}
$$

where $A, B, \bar{S}$ and $\underline{S}$ are to be determined. We are unable to find an analytical solution to this system of equations. The following section provides a numerical solution.

2.5. The value of foreign firms. The option value of investment creates a wedge between the present value of profits and the value of the firm. The value of the exporting firm is the sum of two terms, the present value of the stream of future profits exporting to the foreign market, plus the value of the option to set up a plant in the foreign country and serve the foreign market locally. In this section we analyze how the option to set up a plant in the foreign market affects the value of foreign competitors. To that end, we first value a foreign firm using a procedure very similar to the one used in the previous section.

Let $V_{j}^{*}(S)$ be the value of a foreign firm in state $j=0,1$. In an arbitrage-free economy, it must be the case that the capital gains from owning a foreign firm plus the period profits equal the opportunity costs. Therefore, the value of a foreign firm in each state satisfies 2

$$
\begin{aligned}
& \frac{E\left(d V_{0}^{*}(S)\right)}{d t}+\pi_{0}^{*}(S)=r V_{0}^{*}(S), \\
& \frac{E\left(d V_{1}^{*}(S)\right)}{d t}+\pi_{1}^{*}(S)=r V_{1}^{*}(S) .
\end{aligned}
$$

${ }^{2}$ If the expected depreciation rate is zero and the risk premium is negligible then it is reasonable to discount using the domestic interest rate. Otherwise, we should use the foreign interest rate for discounting. In the latter case, the valuation results change slightly in quantitative terms. 
Appendix A.5 shows that a solution to (15) and (16) has the form

$$
V_{0}^{*}(S)=A^{*} S^{\eta_{0}}+a^{*}+b^{*} S^{-2}+c^{*} S^{-1},
$$

$$
V_{1}^{*}(S)=B^{*} S^{\eta_{1}}+e^{*}
$$

where $a^{*}, b^{*}, c^{*}$ and $e^{*}$ are constants given in Appendix A.5. The value of constants $A^{*}$ and $B^{*}$ are determined by the no-arbitrage or value matching conditions

$$
V_{0}^{*}(\bar{S})=V_{1}^{*}(\bar{S}),
$$

and

$$
V_{0}^{*}(\underline{S})=V_{1}^{*}(\underline{S})
$$

These equations can be solved for constants $A^{*}$ and $B^{*}$ as

$$
\left[\begin{array}{l}
A^{*} \\
B^{*}
\end{array}\right]=\left[\begin{array}{ll}
\underline{S}^{\eta_{0}} & -\underline{S}^{\eta_{1}} \\
\bar{S}^{\eta_{0}} & -{ }^{\eta_{1}}
\end{array}\right]^{-1}\left[\begin{array}{l}
e^{*}-a^{*}-b^{*} \underline{S}^{-2}-c^{*} \underline{S}^{-1} \\
e^{*}-a^{*}-b^{*} \bar{S}^{-2}-c^{*} \bar{S}^{-1}
\end{array}\right]
$$

Notice that the smooth pasting conditions do not hold for the foreign firms, since the decision to go multinational corresponds to the domestic firm.

The economic interpretation of the solution given by (17) and (18) is as follows. The value of a foreign firm is the sum of two terms: the present value of profits plus a bubble term reflecting the effect of the domestic competitor's option. Even though foreign firms in this model are not endowed with the option to invest abroad, the fact that they compete with a firm that does have such an option introduces a wedge between the present value of profits and their value.

The option theory of investment recognizes that the value of a firm is the sum of the present value of profits plus the value of any options the firm might have. The analysis of imperfect competition in the product market shows that, in addition to the net present value of future profits, the value of a firm also includes a term reflecting the effect of options that competitors might have.

\section{NumeriCAl ReSults}

In this section, we obtain a numerical solution to the system of equations (14) for a baseline parameterization. The solution allows us to determine the optimal timing of the investment and the value of the domestic firm. 
Assume that there are no tariffs or transport costs, $\tau=0$, and the inverse demand function is

$$
p=100-Q
$$

Let the parameters of the cost function be the same wherever the production is located with the following values $\gamma=\gamma^{*}=5$ and $\phi=\phi^{*}=60$. The interest rate is chosen to be $r=0.025$, the volatility of the exchange rate $\sigma=0.1$ and the exchange rate drift $\mu=0$. The sunk entry cost is $I=600$ and the exit cost is $L=600$.

Using these parametric values and the nlsys function of the Gauss programming language we find a root to system (14). Let us begin with a monopolistic industry, $N=1$. This is the case when there are no foreign firms and the only supplier is the exporting firm. With this parameter configuration, the trigger exchange rate values are $\underline{S}=0.71$ and $\bar{S}=1.38$. The interpretation of these values is as follows. Suppose that initially the exchange rate is above $\underline{S}$ and the monopolist is exporting to the foreign economy. If $S$ reaches $\underline{S}=0.71$, the domestic monopolist will set up a plant in the foreign country, becoming a multinational firm. However, the firm will only revert to exporting if the exchange rate reaches $\bar{S}=1.38$. This numerical example shows that for reasonable parameter values, the degree of hysteresis can be quite high. In particular, the measure of hysteresis $(\bar{S}-\underline{S}) / \underline{S}=0.94$. Thus, once the domestic firm goes multinational, the exchange rate has to depreciate $94 \%$ before it reverts to exporting.

The numerical solution has been obtained for ten or less firms. When $N=2$ the foreign market is served by the domestic exporter and a local firm, when $N=3$ by the domestic exporter and two local firms, and so on. Figure 2 represents the trigger exchange rates as functions of the number of firms in the industry. 3

As the number of firms increases, $\bar{S}$ rises and $\underline{S}$ diminishes. The degree of hysteresis, $(\bar{S}-\underline{S}) / \underline{S}$, is increasing in the number of firms. There is an intuitive explanation of this results. While sunk costs in foreign currency do not change with the number of firms in the market, the market share of the domestic firm and profits in foreign currency fall. Therefore, as the number of firms increases, the domestic firm will demand a more appreciated currency (a cheaper investment) to set a plant in the foreign country. Analogously, as the number of firms increases, the multinational firm will enjoy lower profits and demand a higher exchange rate to withdraw from the host country to compensate the (constant) sunk cost of delocation.

\footnotetext{
${ }^{3}$ We will show later that, for the parameter values used in the numerical solution, this industry accommodates nine or ten firms in the long-run equilibrium.
} 


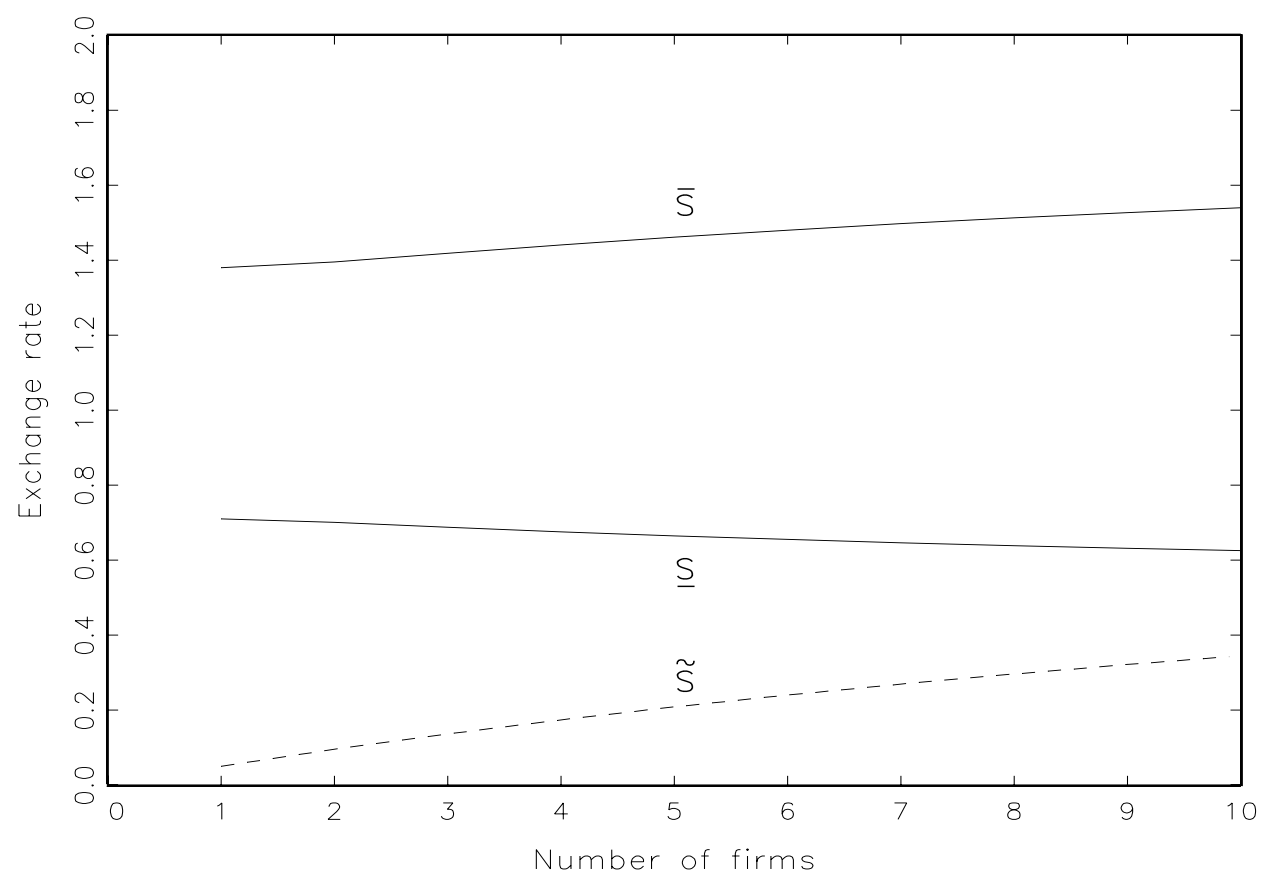

FiguRE 2. This figure shows the trigger exchange rate values $\bar{S}$ and $\underline{S}$, as well as the exchange rate value $\widetilde{S}$ below which optimal production is zero, as functions of the number of firms

For $N=10$ the measure of hysteresis, $(\bar{S}-\underline{S}) / \underline{S}=1.46$, indicates that once the domestic firm goes multinational, it would require a $146 \%$ depreciation for it to revert to exporting.

Notice that in deriving the analytical solution to equations (6) and (7) we assume differentiability and this is guaranteed only if $S \geq \widetilde{S}$. Therefore, it is necessary to verify that, for this parameter configuration, the exchange rate value at which it is optimal for the domestic exporting firm to produce zero units, $\widetilde{S}$, is below the exchange rate $\underline{S}$, at which the domestic firm becomes multinational, as shown in Figure 2.

In addition to finding the trigger exchange rate values and hence determining the timing of the investment, the numerical solution also allows us to compute the value of the domestic firm conditional on the exchange rate and state. Figure 3 shows the value of a domestic firm when the number of firms is $N=9$ (the long-run equilibrium number of firms) in the exporting state, $V_{0}(S)$, and in the multinational state, $V_{1}(S)$. The value of the domestic firm is increasing in the exchange rate in both states. Notice that at the trigger exchange rates, the vertical distance between the two lines equals the domestic currency value of the sunk 


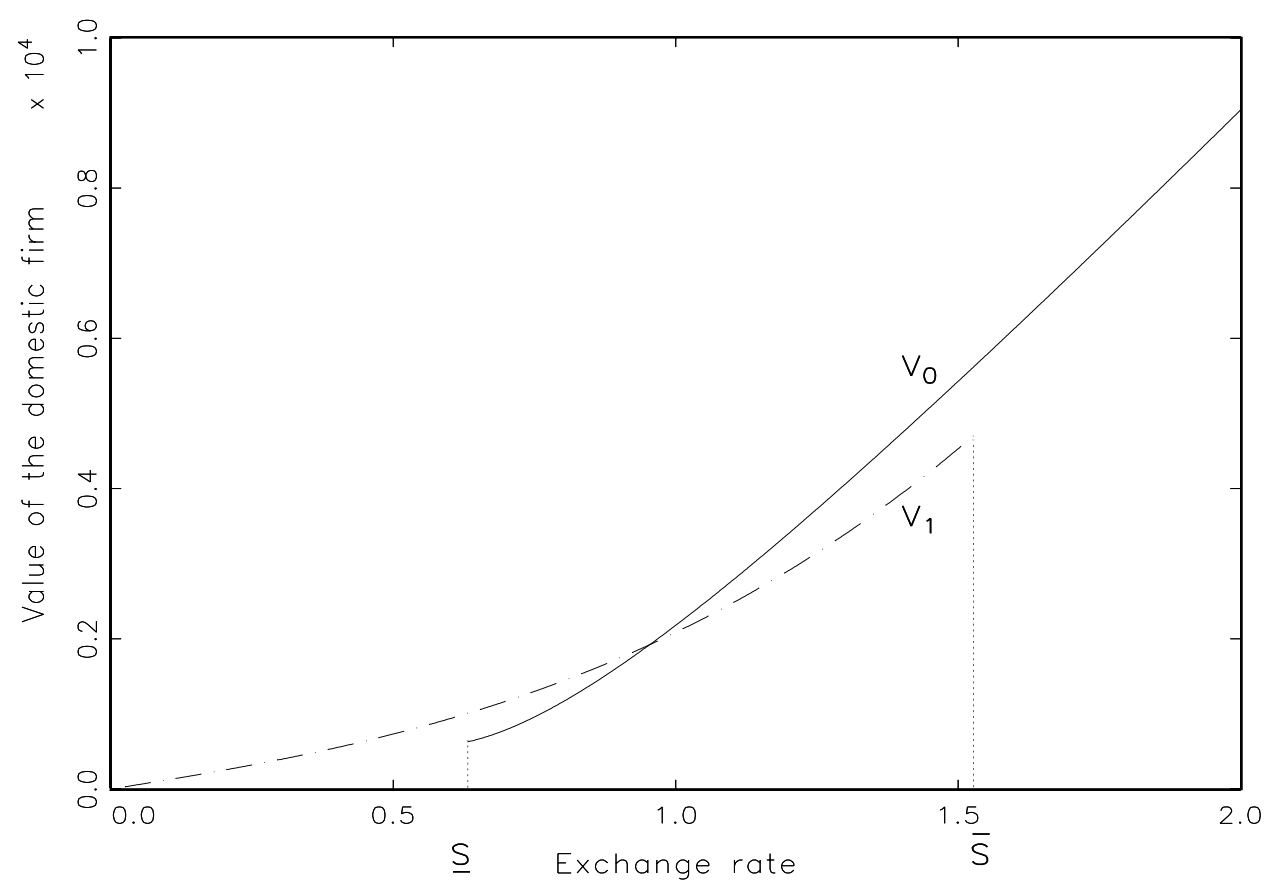

FIgURE 3. This figure shows the value of the dometic firm as a function of the exchange rate when it exports, $V_{0}(S)$, and also when the firm has gone multinational, $V_{1}(S)$. The number of firms is nine.

costs, as the value matching conditions require. The economic interpretation is simple. At the trigger exchange rate $\underline{S}$, the domestic firm is indifferent between continue exporting and going multinational incurring a sunk cost $S L$. Similarly, at the trigger rate $\bar{S}$, the domestic firm is indifferent between staying as a multinational and reverting to exporting paying a sunk cost of $S I$. However, the different scales used in the axis preclude visual inspection of the smooth pasting conditions.

We then computed the value of a typical foreign firm numerically. Figure 4 shows the value of the foreign firm as a function of the exchange rate when the number of firms is the long run number, $N=9$. The graph shows the value of the foreign firm when the domestic firm exports, $V_{0}^{*}(S)$, with a solid line and the value of the foreign firm when the domestic firm has gone multinational, $V_{1}^{*}(S)$, with a broken line. At the trigger exchange rates, $\underline{S}$ and $\bar{S}$, the two lines meet, indicating that the value matching conditions (19) and (20) are satisfied.

To shed some light on this, first suppose that the domestic firm exports and does not have the option to invest abroad. As the exchange rate decreases, the market share of the domestic firm falls and foreign firms increase theirs, and therefore, the market value of foreign firms 


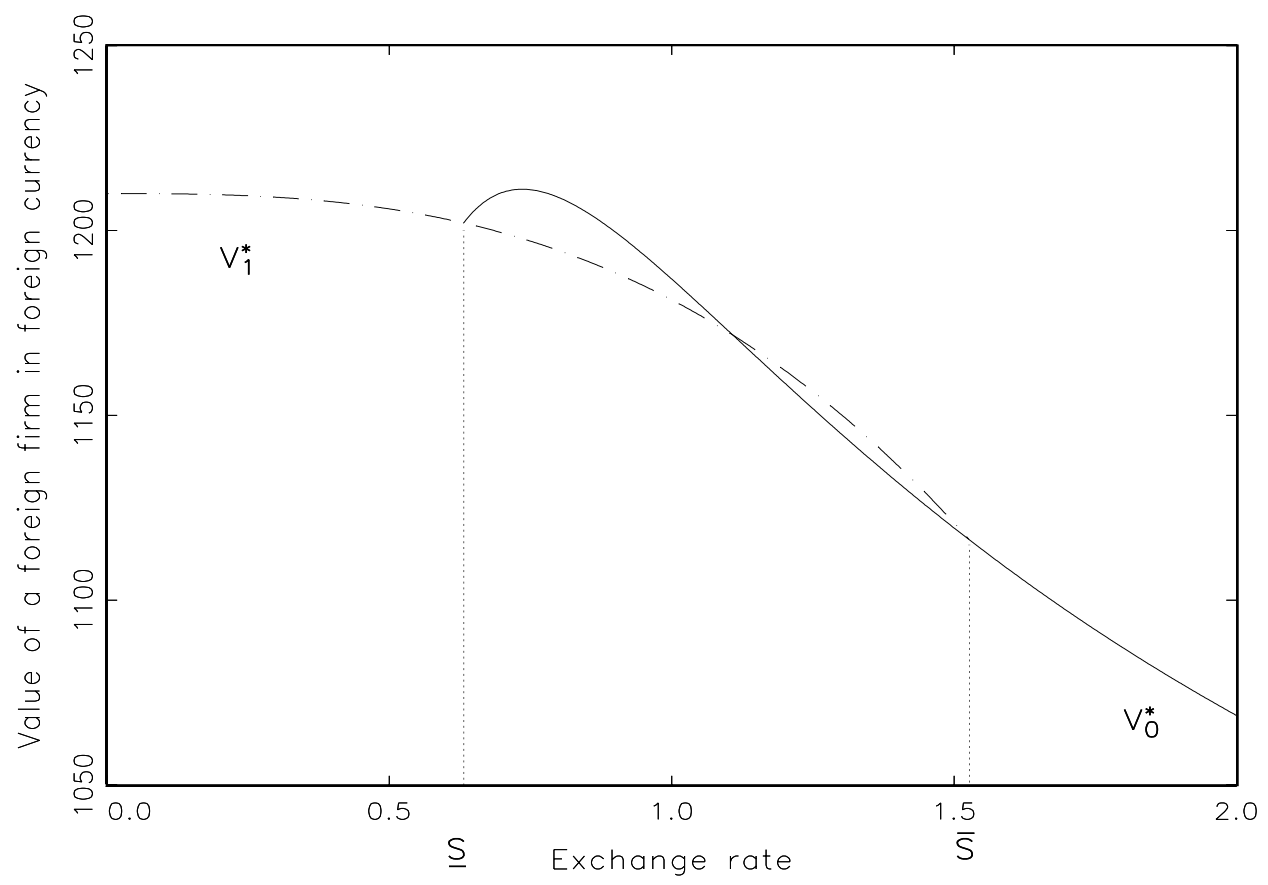

FiguRE 4 . This figure shows the value of a foreign firm as a function of the exchange rate when the domestic firm exports, $V_{0}^{*}(S)$, and also when the domestic firm has gone multinational, $V_{1}^{*}(S)$, when the number of firms is nine.

increases. When the domestic firm is endowed with the option to become multinational, the value of the foreign firm is defined for exchange rate values above $\underline{S}$. As the exchange rate approaches $\underline{S}$, precisely when the option is more likely to be exercised, the value of the foreign firm decreases. Next consider the case when the domestic firm is multinational, thus $S<\bar{S}$. In this state, market shares do not depend on the exchange rate. However, the value of foreign firms does depend on the exchange rate. As the exchange rate depreciates, the domestic firm is more likely to revert to exporting, thus affecting the value of foreign firms negatively, and more so the closer the exchange rate is to the trigger value $\bar{S}$.

Finding the value of foreigns firm allows us to say something about industry dynamics. Suppose foreign firms can freely enter or exit the market but domestic ones cannot. Figure 5 depicts the value of a foreign firm when there are nine or ten firms in the industry. According to Figure 5, if there were eight firms in the market, a foreign firm would enter the market since its market value in either state would be greater than the initiation cost, $I=600$, represented by the horizontal line. However, if there were initially nine firms, entry does not take place as the value of the tenth firm would be lower than the initiation cost uniformly in $S$. If for 


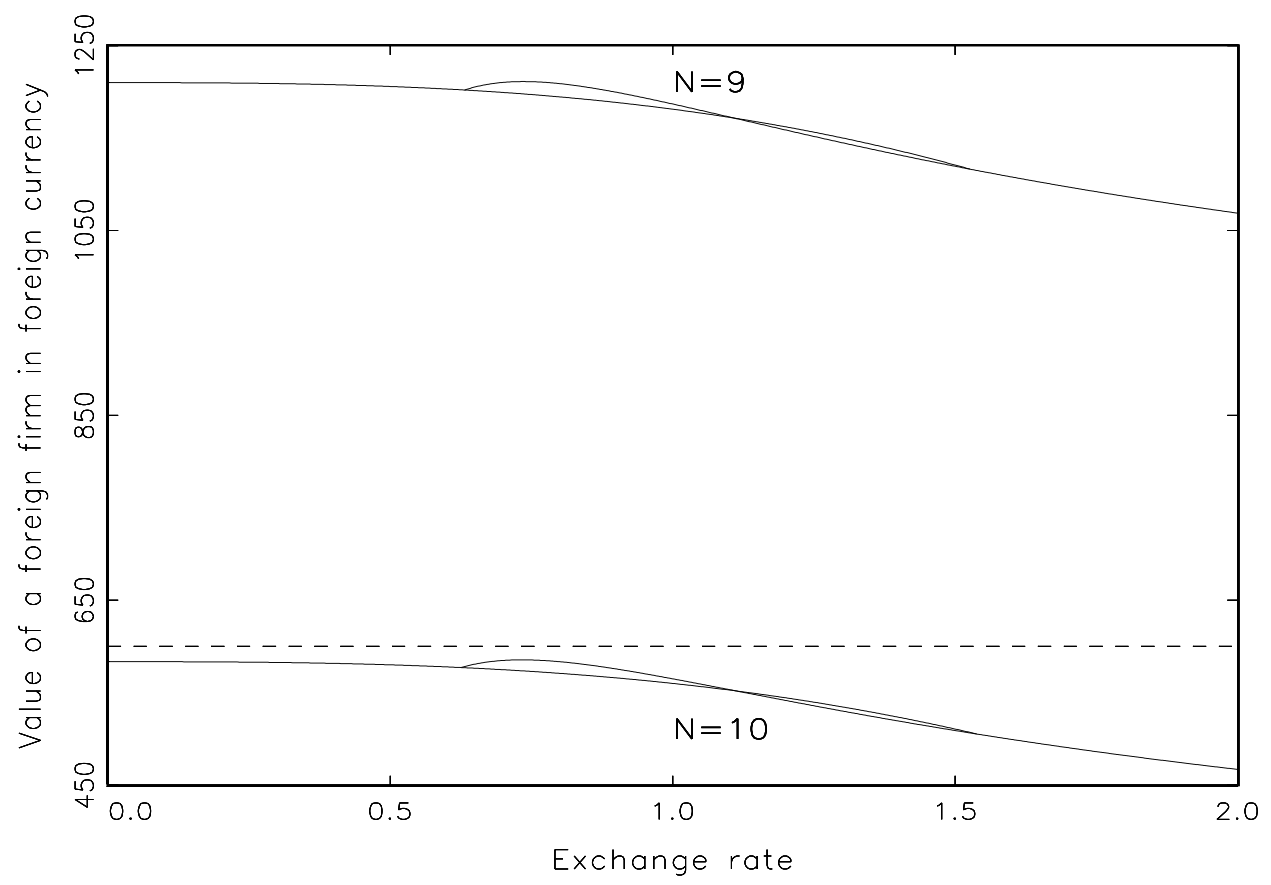

FiguRE 5. This figure shows the value of a foreign firm as a function of the exchange rate in both states when the number of firms is nine and ten. The horizontal line represents the entry cost.

historical reasons there were ten firms in the market, none of them would quit the market, as all of them would enjoy positive profits. Therefore, the equilibrium number of firms is nine or ten. This market does not accommodate eleven profit making firms.

\section{FDI, EXPORTS AND DUMPING}

When production requires a sunk maintenance cost, the exporting firm may incur dumping. Notice that since the exporting firm does not sell in the home country, international price discrimination cannot occur. However, when there is a sunk maintenance cost, dumping may arise because the domestic firm may optimally decide to export at a loss.

Figure 6 shows entry and exit trigger exchange rates as well as $\widehat{S}$, the only root of $\pi_{0}(S)=0$. For exchange rates below $\widehat{S}$ and above $\underline{S}$, the domestic firm dumps on the foreign market. When the number of firms is below 7, dumping never appears because the domestic firm goes multinational before the exchange rate hits the dumping trigger exchange rate, that is $\underline{\mathrm{S}}>\widehat{S}$. Dumping appears for more competitive industries, with seven or more firms, where the exporting firm may find it optimal to export at a loss for exchange rates in the interval 


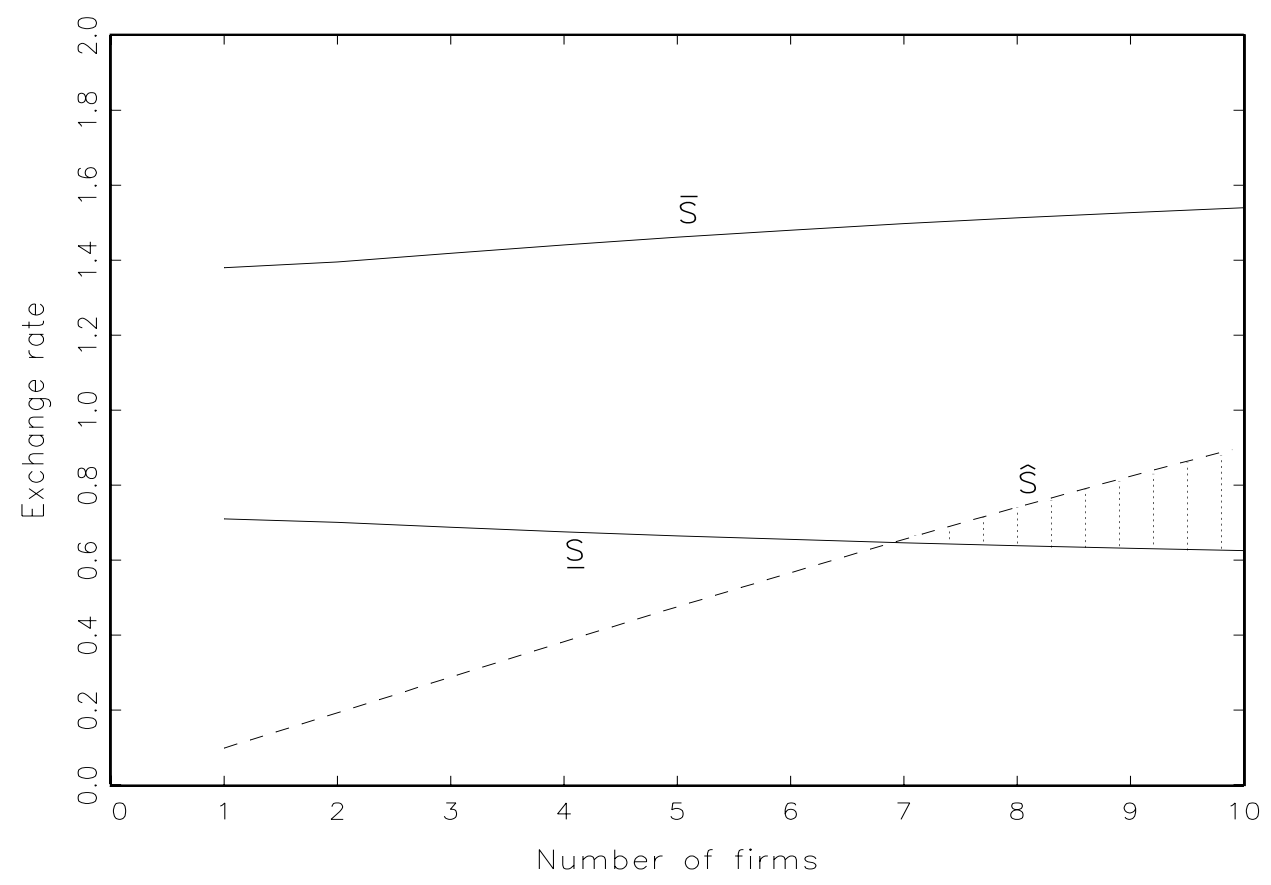

FiguRE 6. This figure shows the "dumping region" with vertical stripes where $N \in$ $\{7,8,9,10\}$ and $S \in(\underline{S}, \widehat{S})$.

$(\underline{\mathrm{S}}, \widehat{S})$. Notice that in this scenario the operating profits of the exporting firm are negative, and therefore the expected present value of exporting (and remaining in that state forever) is negative. Why should the domestic firm be interested in exporting if the present value of that activity is negative? The reason is that the value of the exporting firm is the sum of two terms: the present value of exporting plus the value of the option to become multinational. When dumping appears, the present value of exporting is negative, but the value of the option to become multinational is positive and offsets the negative present value of exporting. Furthermore, while the exporting firm dumps the value of being multinational is greater than the initiation cost, i.e. $V_{1}(S)>I S$. Therefore, the orthodox theory of investment would suggest going multinational instead of losing money by exporting. However, waiting is a better strategy since $V_{0}(S)>V_{1}(S)-I S$. The domestic firm keeps on exporting and waits: if the domestic currency depreciates, it will continue exporting, but in case of an appreciation that takes the exchange rate below $\underline{S}$, it will go multinational. Therefore, this type of dumping is temporary. 
Notice that dumping only takes place when the number of firms is large enough. This is just a matter of the specific parameter values used in the numerical solution. We have verified that higher values of the maintenance cost, $\phi$, reduce the number of firms necessary for dumping to appear. ${ }^{4}$ In the extreme case of a huge maintenance cost, even a monopolist could incur dumping. On the opposite side, as the maintenance cost tends to zero, the dumping region disappears. Similarly, a lower value of parameter $\alpha$, or higher values of $\beta$ and $\gamma$ render a dumping region that includes smaller numbers of firms. What remains true in all these parameter changes is that with a positive maintenance cost dumping appears when the number of firms is close to its the long run equilibrium value.

International trade literature has explored several situations where dumping may appear. However, the type of dumping we analyze has not been fully characterized before. Sometimes dumping appears when a government subsidizes a firm. In our model, this situation would correspond to setting $\tau$ below zero. The parametric configuration used in drawing Figure 6 , however, sets export subsidies to zero. So dumping is not of this sort. An exporting firm may often incur temporary loses to drive competitors out of the market, as suggested by Davies and McGuiness (1982). However, in our model, when the domestic firm is dumping in the foreign market, it does not do so to get rid of competitors since local firms enjoy positive profits. Therefore, dumping is not predatory. Since we are studying a single market, there cannot be international price discrimination, so dumping is not persistent (e.g. Brander and Krugman, 1983). Neither is this type of dumping sporadic, as would be the case if the exporting firm was getting rid of unsold stocks.

This dumping is of the sort found by Sercu and Vanhulle (1992), who show how an exporting firm "will dump when re-entry entails a cost".5 In Sercu and Vanhulle's model the firm does not have the option to go multinational. In their setting, the firm exports and retains the option of closing down or stays out of business and retains the option to re-enter the market. Their model can be cast as a special case of ours where the domestic firm does not have the option to go multinational but may close down the local plant. Considering this special case helps to understand our model. To that end we have numerically solved the model for exactly the same parameter configuration used to draw Figure 6 except that we do not allow the

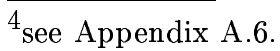

${ }^{5}$ Sercu and Vanhulle (1992) cite the working paper versions of Dixit (1989a, 1989b) and Delgado (1991) where this type of dumping was apparently first mentioned.
} 


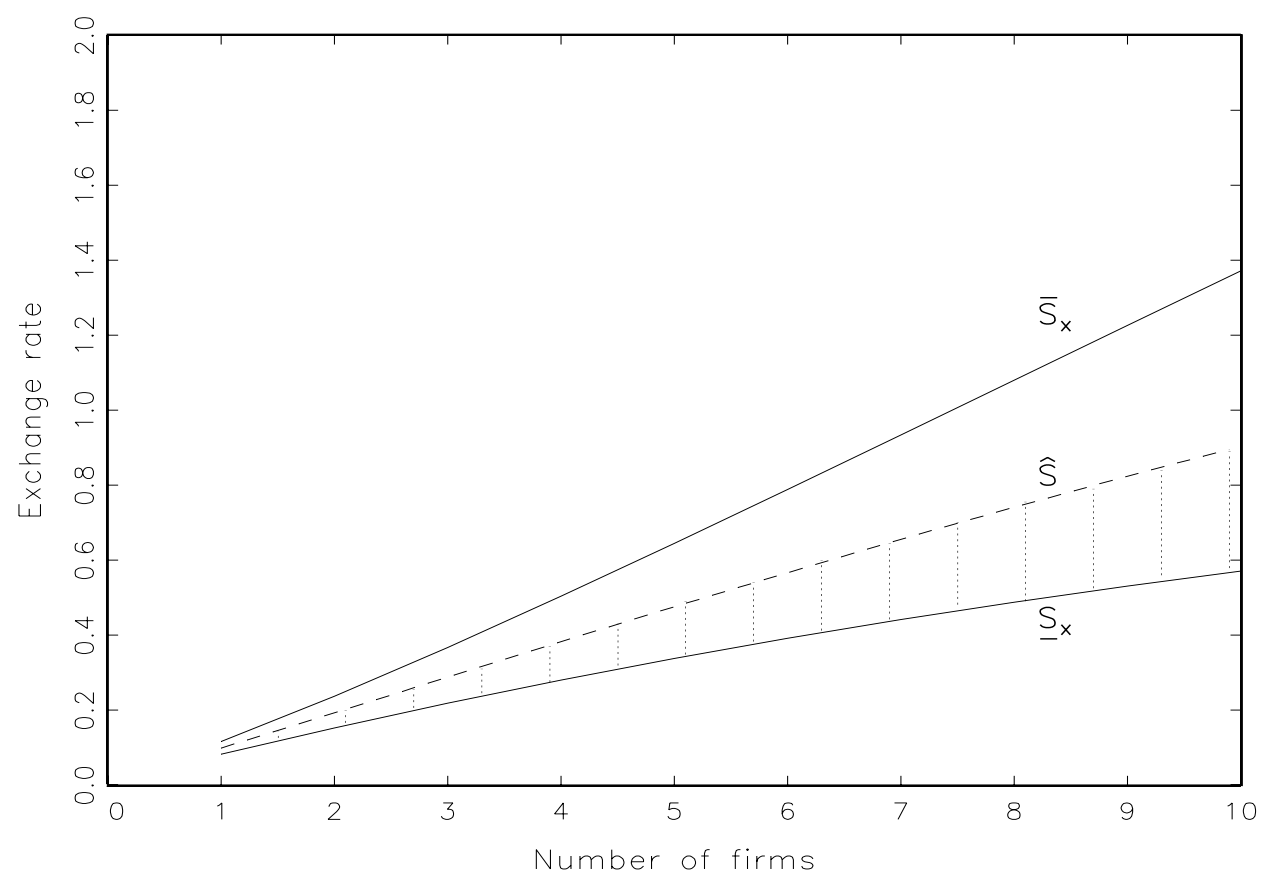

FiguRE 7 . This figure shows the exchange rate values $\bar{S}_{x}$ and $\underline{S}_{x}$ that trigger exporting and closing down as functions of the number of firms. The dumping trigger exchange rate $\widehat{S}$ is exactly the same as in Figure 6 . The exchange rate dumping range is shown with shading.

domestic firm to go multinational. Mathematically, this corresponds to the case where $e=0$. Figure 7 shows the exchange rate trigger values when the only alternative to exporting is closing down. The exchange rate trigger values $\bar{S}_{x}$ and $\underline{S}_{x}$ now have a different interpretation. Suppose the domestic firm exports and the exchange rate is above $\underline{S}_{x}$. If the exchange rate falls below $\underline{S}_{x}$ the firm stops production. The idle firm will resume production for the foreign market when the exchange rate hits the exchange rate value $\bar{S}_{x}$ from below. The degree of hysteresis is increasing with the number of firms. When exporting is the only way to reach the foreign market, dumping may appear for exchange rate values in the interval $\left(\widehat{S}, \underline{S}_{x}\right)$ and any number of firms. When the number of firms is low, the range of exchange rate values for which dumping may appear is very narrow and widens as the number of firms grows.

Next we compare the two situations considered above: when the firm can either export or quit and when the firm can export or go multinational. To that end we have combined Figures 6 and 7 in Figure 8. 


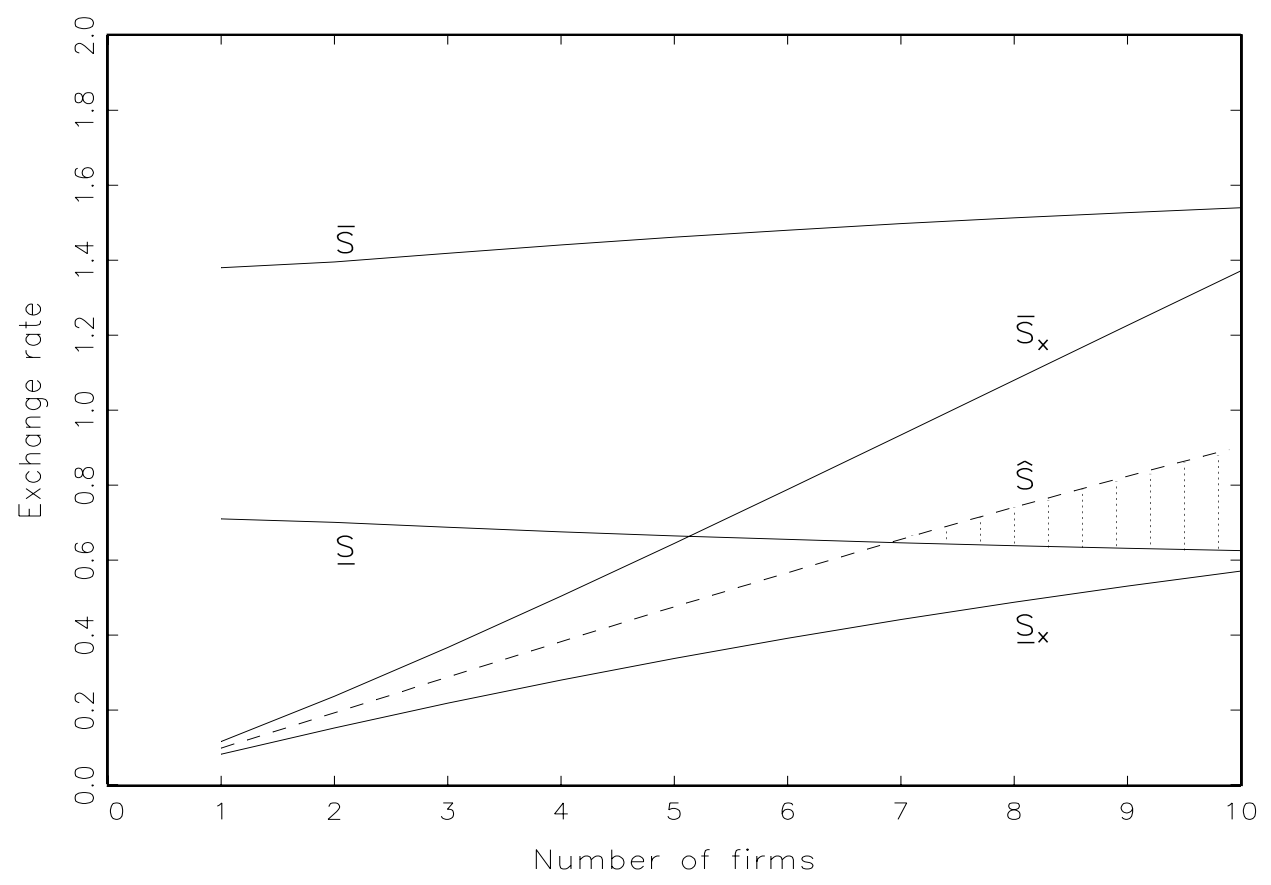

Figure 8. This Figure shows Figures 6 and 7 together. The "dumping region" is shown with shading.

To the extent that international trade and factor mobility are substitutes, when we allow an exporting firm to set up a plant in a foreign country, we should expect it to replace exports by FDI, thus eliminating dumping. This is in fact the case for market structures with a low number of firms. However, when the number of firms is large enough, this type of dumping persists after we endow the firm with the option to go multinational. This is the novelty of this type of dumping. Not only does it appear when exporting is the only way to reach the foreign market, but also when countries are open to FDI flows. The intuition why FDI can remove dumping in less competitive industries while it cannot in more competitive settings is simple. Allowing for FDI amounts to endowing the domestic firm with an option to invest abroad. However, allowing FDI flows does not imply that the domestic firm will exercise the option to invest. In market settings with seven or more firms and with the exchange rate in the dumping region, the domestic firm does not exercise the option to go multinational and waits for the domestic currency to appreciate enough before incurring the sunk cost of setting up a plant in the foreign market. While waiting for more favorable conditions and with the exchange rate in the dumping region, the domestic firm dumps into the foreign market. 
Incidentally, Figure 8 also shows that if the exporting firm has the option to go multinational and the option to close down its business, the latter will never be exercised, as $\underline{S}$ is greater than $\underline{S}_{x}$

The interval $(\underline{S}, \widehat{S})$ is the range of exchange values that generate dumping. Of course, this interval is well defined only for $N \geq 7$. This interval is wider the larger the number of firms. Notice that, conditional on any given value of the exchange rate, the wider this interval, the higher the probability of observing dumping. Comparing this interval in Figures 7$]$ and 8 , we see that the option to incur FDI expense eliminates the possibility of dumping when the dumping interval is narrow, and dumping is therefore less likely, but it cannot be ruled out when the interval is wider, and hence it is more likely. Furthermore, the parametric values used in the numerical solution given in Figure 8 imply that the long run equilibrium number of firms in the foreign market is nine or ten. Therefore, FDI cannot remove dumping precisely when the number of firms approaches the long run number.

The empirical evidence provided by Knetter and Prusa (2003) suggests that a real appreciation of the importing country's currency increases anti-dumping filings. In this model, however, dumping appears when the currency of the importing country is sufficiently depreciated. It could be the case that, as Knetter and Prusa (2003) are inclined to think, foreign firms are held responsible for factors beyond their control. For instance, Lee and Mah (2003) present evidence supporting the view that the US International Trade Commission's injury decisions are influenced by increased import penetration. In the latter case, antidumping laws allow abuse of the statute.

\section{TARIFFS}

In this section, we study the effect of tariffs on the exchange rate values that trigger FDI. Figure 9 plots the trigger exchange rates when $\tau=0$ and $\tau=0.1$, a $10 \%$ tariff rate. An increase in the tariff makes $\bar{S}$ and $\underline{S}$ rise, thus making FDI a more attractive choice ${ }^{6}$ The fact that a tariff makes FDI more likely is in line with the literature on tariff-jumping FDI.7]

The contribution here is twofold. First, the FDI-inducing effect of a tariff is smaller the larger the number of firms in the industry. This result is intuitively appealing, as increased

\footnotetext{
${ }^{6}$ For higher tariff rates, we are unable to find a solution for market structures with few firms ${ }^{7}$ See Motta (1992) for tariff-jumping FDI and Belderbos, Vandenbussche and Veugelers (2004) for antidumping jumping FDI.
} 


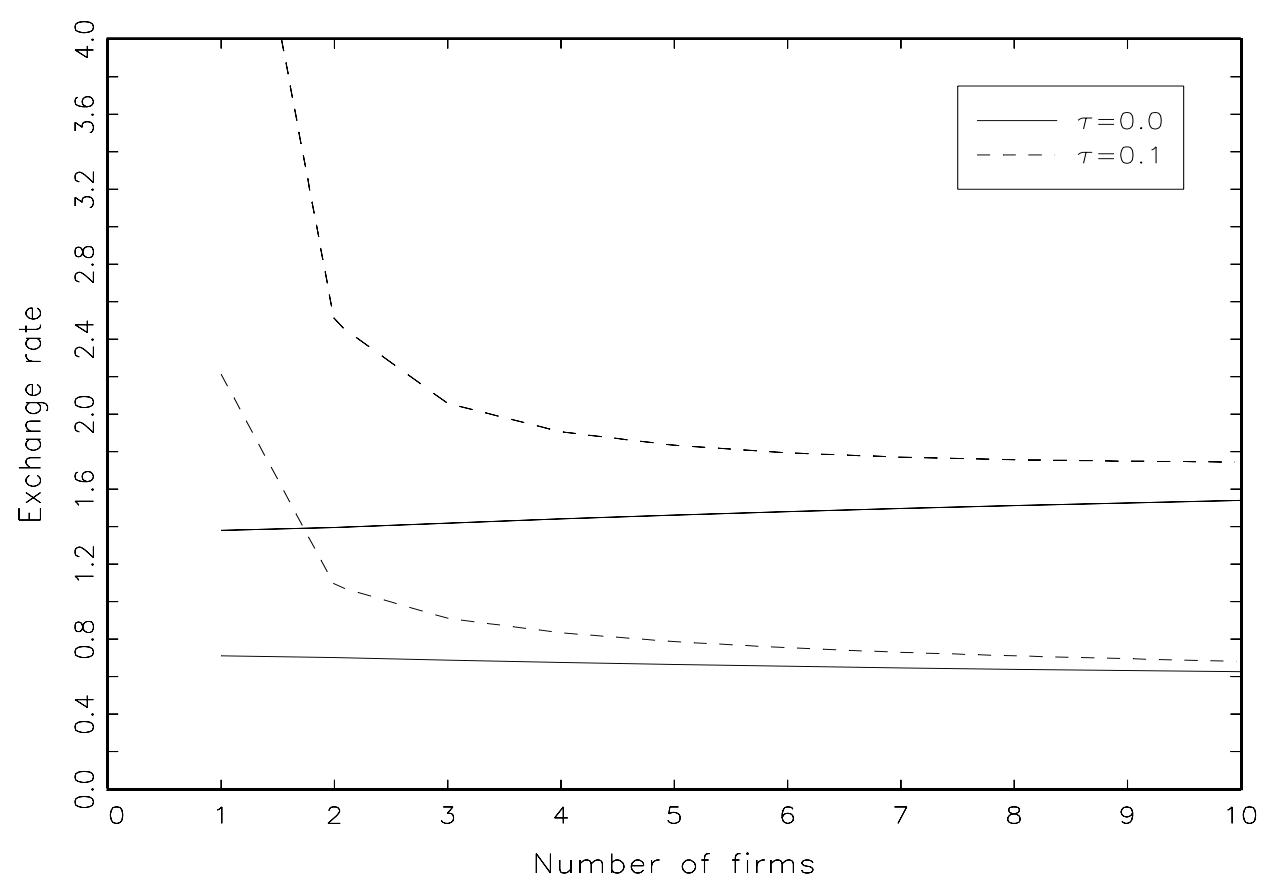

FiguRE 9. This figure illustrates the effect of an increase in the tariff rate from zero (solid lines) to $\tau=0.1$ (broken lines) on $\bar{S}$, and $\underline{S}$. Notice the difference with previous figures: the exchange rate measured on the y-axis ranges from 0 to 4 .

competition makes FDI less attractive. Second, as Figure 9 shows, a tariff extends the range of exchange rate values for which going multinational makes sense. Notice that $\bar{S}$ rises much more than $\underline{S}$. This suggests that a tariff may be used not only to induce the exporting firm to go multinational but also, and more effectively, to deter it from delocating.

Tariffs also affect dumping. Figure 10 illustrates the relationship between the exchange rate and the tariff rate when there are nine firms. An increase in the tariff rate raises the the dumping trigger exchange rate $\widehat{S}$ and the FDI trigger exchange rate $\underline{S}$. For a given tariff rate, an exchange rate in the interval $(\underline{S}, \widehat{S})$ generates dumping. Figure 10 exhibits a striking result: a rise in the tariff rate may induce dumping. Suppose that the combination of tariff and exchange rates corresponds to point $A$ in Figure 10, that is, a $10 \%$ tariff rate with an exchange rate of one. An increase in the tariff rate from $10 \%$ to $30 \%$ with the exchange rate remaining constant, represented in Figure 10 by point $B$, would induce dumping. Therefore, a tariff might have the undesired effect of generating dumping. This implies that if antidumping duties are applied when dumping does not exist but is close to occurring, as in point $A$, it is the 


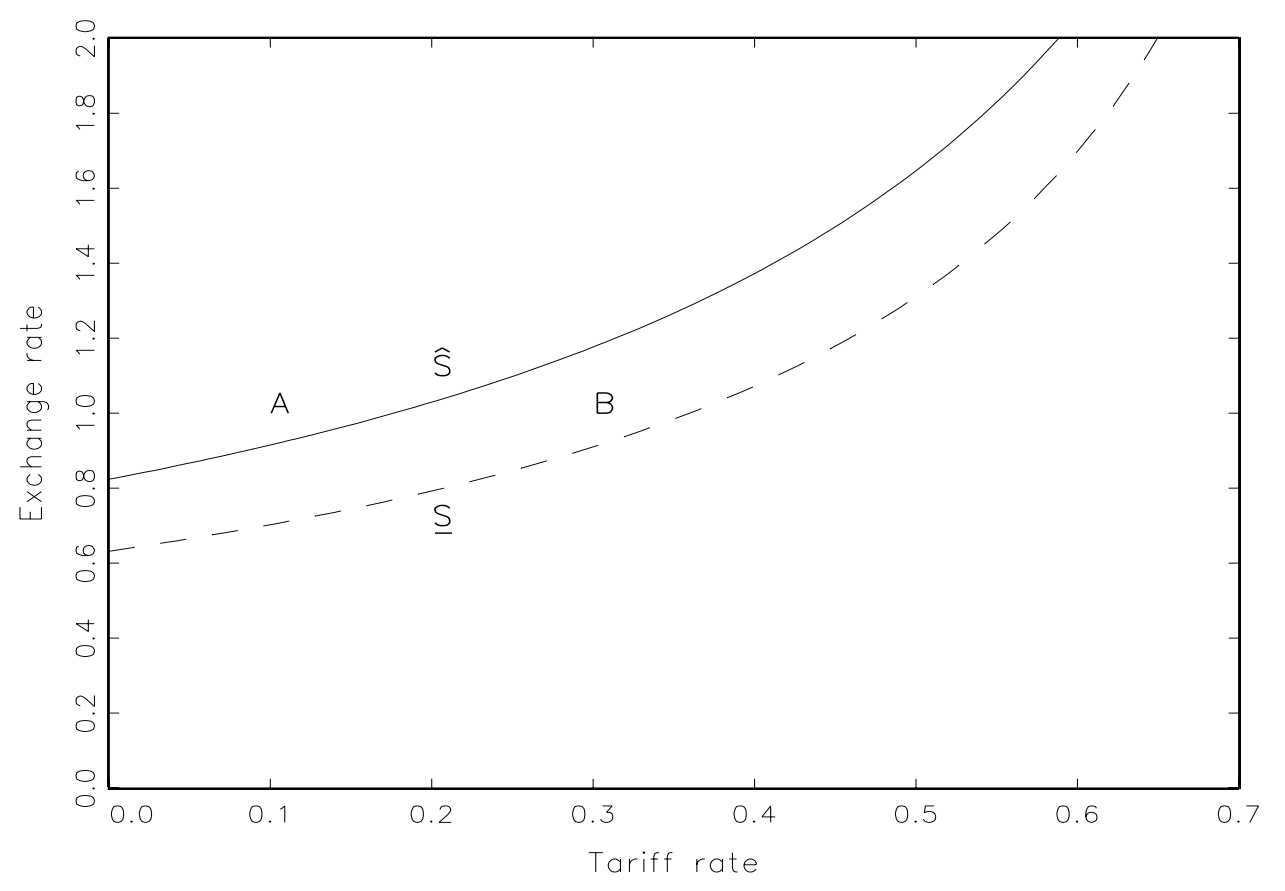

FIGURE 10. This figure illustrates the relationship between the exchange rate dumping range and the tariff rate when the number of firms is nine.

protective measure itself that can generate dumping. The results of this section suggest that, as Nelson (2006) indicates, antidumping duties are a particularly bad protective measure.

\section{Robustness of Results}

The results shown in this paper correspond to a numerical solution for specific functional forms and parameter values. Therefore, it is logical to question how robust the results are with respect to these two sets of assumptions: functional forms and parameter values. As for the functional forms used, we assume that the demand and cost functions are linear. An analytic solution to the Cournot equilibria can also be obtained for quadratic demand and/or cost functions. However, we are unable to find an analytic solution to equations 6 and 7 when demand and/or costs functions depart from linearity and therefore cannot use the preceding option pricing technique. In order to investigate the robustness of our numerical results with respect to the specific parameter values used, we have solved system 14 for different values of $\alpha, \beta, \gamma, \phi, \sigma, \mu, I$ and $L$. Since the parameter space is highly dimensional, a grid search is infeasible. Instead, we have searched the parameter space changing the value of one parameter 
at a time and maintaining the value of the other parameters equal to the benchmark case. The results shown above obtain qualitatively, although changing the parameter values does change the results quantitatively. However, these quantitative changes are very intuitive, almost trivial. For instance, increasing the value of $\alpha$ and holding the other parameters constant increases profits and thus results in a higher long run equilibrium number of firms. The results obtained in this manner are very similar to those reported in Dixit (1989a) and would be very lengthy to state without adding new insights to the analysis. Thus, we decided to include them in Appendix A.6.

\section{Conclusions}

We develop a model of an exporting firm competing in a foreign oligopolistic market under exchange rate uncertainty. The exporting firm has the option to set up a plant in the foreign country, thus creating a FDI flow. Real option pricing techniques are used to determine the optimal timing rule of the investment.

Let us enumerate the results obtained. First, we find that the degree of hysteresis grows with the number of firms in the industry. Second, we are able to compute the market value of the domestic firm and, more importantly, of foreign competitors taking into account the effect of the option held by the domestic producer. The option theory of investment recognizes that the value of the firm should include not only the present value of profits, but also the value of all options the company might have. The strategic interaction of firms in the product market implies that the value of a firm is affected by any options that competitors might have. Third, when an exporting firm has the option to go multinational and there are sunk maintenance costs, dumping can ocurr. This type of dumping appears when the number of firms is large enough and close to the long run equilibrium number of firms. When the firm exports and has the option to close down its business, the firm might optimally decide to export at a loss, as re-entry into the market has a cost. This is the well know option value of staying in business even when you might have losses in the short run. However, in our model the exporting firm has the option to stop production domestically and set up a profit making plant in the foreign country. Endowed with this option, the domestic firm never exercises the option of closing down its business. When the number of firms is low, the option to set up a plant in the foreign country eliminates the possibility of dumping. However when the number of firms is close to 
the long run equilibrium number of firms the option to invest abroad does not eliminate the possibility of dumping. Fourth, we find that tariffs have the well known FDI-inducing effect, more so in less competitive markets. The contribution here is the finding that tariffs are more effective at deterring delocation. Fifth, a tariff (or anti-dumping duty) might have the undesired effect of inducing dumping. 


\section{A.1. Market equilibrium When Exporting}

The exporting firm maximizes

$$
\pi\left(q_{0}\right)=S(1-\tau)\left(\alpha-\beta Q_{0}\right) q_{0}-\phi-\gamma q_{0} .
$$

The first order condition is

$$
\frac{\partial \pi\left(q_{0}\right)}{\partial q_{0}}=S(1-\tau)\left(\alpha-\beta Q_{0}-\beta q_{0}\right)-\gamma=0
$$

which gives the reaction function of the exporting firm

$$
q_{0}=\frac{S(1-\tau)\left(\alpha-\beta \sum_{i=1}^{N-1} q_{i 0}^{*}\right)-\gamma}{2 \beta S(1-\tau)} .
$$

Foreign firm $i$ maximizes

$$
\begin{aligned}
& \pi\left(q_{i 0}^{*}\right)=\left(\alpha-\beta Q_{0}\right) q_{i 0}^{*}-\phi^{*}-\gamma^{*} q_{i 0}^{*} \\
& \frac{\partial \pi\left(q_{i 0}^{*}\right)}{\partial q_{i 0}^{*}}=\alpha-\beta Q_{0}-\beta q_{i 0}^{*}-\gamma^{*}=0 .
\end{aligned}
$$

which gives the reaction function of foreign firm $i$

$$
q_{i 0}^{*}=\frac{\alpha-\beta\left(q_{0}+\sum_{l \neq i}^{N-1} q_{l 0}^{*}\right)-\gamma^{*}}{2 \beta} .
$$

Since all foreign firms are identical

$$
\sum_{i=1}^{N-1} q_{i 0}^{*}=(N-1) q_{0}^{*} .
$$

The production levels of the exporting firm and a typical foreign firm are

$$
\begin{aligned}
q_{0} & =\frac{S(1-\tau)\left(\alpha+(N-1) \gamma^{*}\right)-N \gamma}{\beta(N+1) S(1-\tau)} \\
q_{0}^{*} & =\frac{S(1-\tau)\left(\alpha-2 \gamma^{*}\right)+\gamma}{\beta(N+1) S(1-\tau)} .
\end{aligned}
$$

The optimal output of the domestic firm is positive for all exchange rates such that

$$
S \geq \frac{N \gamma}{(1-\tau)\left(\alpha+(N-1) \gamma^{*}\right)}=\widetilde{S}
$$

Therefore, total output is

$$
Q_{0}=\frac{S(1-\tau)\left(N \alpha-(N-1) \gamma^{*}\right)-\gamma}{\beta(N+1) S(1-\tau)}
$$

Operating profits when exporting are

$$
\pi_{0}(S)=S(1-\tau)\left(\alpha-\beta Q_{0}\right) q_{0}-\phi-\gamma q_{0} .
$$


Substituting the optimal production values of the domestic and foreign firms yields equation (3)

\section{A.2. Market equilibrium when Multinational}

The multinational firm maximizes the following function

$$
\pi\left(q_{1}\right)=S\left[\left(\alpha-\beta Q_{1}\right) q_{1}-\phi^{*}-\gamma^{*} q_{1}\right] .
$$

The first order condition is

$$
\frac{\partial \pi\left(q_{1}\right)}{\partial q_{1}}=S\left(\alpha-\beta Q_{1}-\beta q_{1}-\gamma^{*}\right)=0
$$

and the reaction function of the multinational is

$$
q_{1}=\frac{\alpha-\beta\left(\sum_{i=1}^{N-1} q_{i 1}^{*}\right)-\gamma^{*}}{2 \beta} .
$$

Foreign firm $i$ maximizes

$$
\pi\left(q_{i 1}^{*}\right)=\left(\alpha-\beta Q_{1}\right) q_{i 1}^{*}-\phi^{*}-\gamma^{*} q_{i 1}^{*} .
$$

Since the objective function is the same as the objective function of the multinational up to a scale factor, the solution is the same. The production levels of the multinational and local firms are

$$
q_{1}=q_{11}^{*}=q_{21}^{*}=\ldots .=\frac{\alpha-\gamma^{*}}{\beta(N+1)} .
$$

So total production is

$$
Q_{1}=\frac{N\left(\alpha-\gamma^{*}\right)}{\beta(N+1)} .
$$

The operating profit of the multinational firm will be

as in equation (4).

$$
\begin{gathered}
\pi_{1}(S)=S\left[\left(\alpha-\beta Q_{1}\right) q_{1}-\phi^{*}-\gamma^{*} q_{1}\right] \\
\pi_{1}(S)=S\left[\frac{1}{\beta}\left(\frac{\alpha-\gamma^{*}}{N+1}\right)^{2}-\phi^{*}\right],
\end{gathered}
$$

\section{A.3. Risk neutral Valuation}

There are two ways of finding the price of the domestic firm: dynamic programming and contingent claims analysis. Let us first consider the dynamic programming approach. Let $V_{j}(S$,$) be the value of the firm in state j$, with $j=0,1$. The firm generates profits in each period, $\pi_{j}(S)$. Let $\rho$ be the appropriate discounted rate, interpreted as the return the 
investor could obtain from alternative investment projects with similar risk characteristics. A convenient way of writing the Bellman equation is as follows

$$
\frac{E\left(d V_{j}(S)\right)}{d t}+\pi_{j}(S)=\rho V_{j}(S) .
$$

Equation (23) makes explicit the idea that the ownership of a flow of profits is an asset whose value is $V_{j}(S)$. On the right-hand side, we write the normal return per unit of time that the investor using the discounted rate $\rho$, would require to hold this asset. On the left-hand side, the first expression is the expected capital gain and the second is the instantaneous profit that the asset pays. Equation (23) is a no-arbitrage or equilibrium condition expressing the willingness to hold the asset. Applying Ito's lemma we get

$$
\frac{1}{2} \sigma^{2} S^{2} V_{j}^{\prime \prime}(S)+\mu S V_{j}^{\prime}(S)+\pi_{j}(S)=\rho V_{j}(S)
$$

Equation (24) is an ordinary second order differential equation where $S$ is the only independent variable.

Next, let us consider the contingent claim analysis. The basic idea is that in an economy with a rich menu of traded assets with different risk and return characteristics, we can value a new asset through a portfolio of existing traded assets. The value of the new asset must be equal to the market value of the replicating portfolio, as any discrepancy would imply an arbitrage opportunity.

Consider the simple case where the investor has the opportunity to invest one unit of domestic currency in a riskless asset with a return exogenously specified, $r$, and buys $n$ shares in a foreign firm. For the sake of simplicity, assume that the share price, $P^{*}$, does not vary, so the only source of uncertainty comes from the exchange rate movements. The total cost of the portfolio is $1+n S P^{*}$. If the investor holds the portfolio for a short period of time, $d t$, the riskless asset pays the sure return, $r d t$, while the foreign investment portfolio pays a convenience yield, $\delta$, such that the investor obtains $\delta n S P^{*} d t$ units of domestic currency over a period of time of length $d t$. Therefore, the portfolio generates profits in domestic currency of $r d t+\delta n S P^{*} d t$. On the other hand, as $S$ follows a stochastic process, a random capital gain will also be obtained

$$
n P^{*} d S=n S P^{*} \mu d t+n S P^{*} \sigma d z .
$$

Finally the total return per unit of domestic currency invested is

$$
\frac{r d t+\delta n S P^{*} d t+n S P^{*} \mu d t+n S P^{*} \sigma d z}{1+n S P^{*}}=\frac{r+n S P^{*}(\mu+\delta)}{1+n S P^{*}} d t+\frac{n S P^{*} \sigma}{1+n S P^{*}} d z .
$$


The ownership of the domestic firm for the same period of time $d t$ would be valued $V_{j}(S)$, generates a known flow of profits, $\pi_{j}(S) d t$, and an expected capital gain of $d V_{j}(S)$. Using Ito's lemma we obtain

$$
d V_{j}(S)=\left[\frac{1}{2} \sigma^{2} S^{2} V_{j}^{\prime \prime}(S)+\mu S V_{j}^{\prime}(S)\right] d t+\sigma S V_{j}^{\prime}(S) d z .
$$

The total return of owning the domestic firm per unit of domestic currency invested is

$$
\frac{\left[\pi_{j}(S)+\frac{1}{2} \sigma^{2} S^{2} V_{j}^{\prime \prime}(S)+\mu S V_{j}^{\prime}(S)\right]}{V_{j}(S)} d t+\frac{\sigma S V_{j}^{\prime}(S)}{V_{j}(S)} d z .
$$

If the ad-hoc portfolio constructed earlier replicates the risk of owning the domesting firm, it has to be the case that

$$
\frac{n S P^{*}}{1+n S P^{*}}=\frac{S V_{j}^{\prime}(S)}{V_{j}(S)} .
$$

Moreover, we know that market equilibrium implies that two assets with the same risk must pay the same return. Therefore, under no arbitrage opportunities it must be the case that

$$
\frac{\left[\pi_{j}(S)+\frac{1}{2} \sigma^{2} S^{2} V_{j}^{\prime \prime}(S)+\mu S V_{j}^{\prime}(S)\right]}{V_{j}(S)}=\frac{r+n S P^{*}(\mu+\delta)}{1+n S P^{*}} .
$$

Using (25) and (26), we obtain

$$
\frac{1}{2} \sigma^{2} S^{2} V_{j}^{\prime \prime}(S)+(r-\delta) S V_{j}^{\prime}(S)+\pi_{j}(S)=r V_{j}(S) .
$$

Notice that (27) is similar to (24) with the difference that $r$ takes the place of $\rho$ and $r-\delta$ is written instead of $\mu$.

\section{A.4. Solutions to equations (6) And (7).}

To solve equations (6) and (7), use It $\widehat{o}$ 's Lemma in each case to obtain

$$
\begin{aligned}
& \frac{1}{2} \sigma^{2} S^{2} V_{0}^{\prime \prime}(S)+\mu S V_{0}^{\prime}(S)-r V_{0}(S)=-\pi_{0}(S), \\
& \frac{1}{2} \sigma^{2} S^{2} V_{1}^{\prime \prime}(S)+\mu S V_{1}^{\prime}(S)-r V_{1}(S)=-\pi_{1}(S) .
\end{aligned}
$$

Equations (28) and (29) have the same homogeneous part, so the solution to the homogeneous part must be the same. Trying a complementary function $g(S)=S^{\eta}$ yields

$$
\frac{1}{2} \sigma^{2} \eta(\eta-1) S^{\eta}+\mu \eta S^{\eta}-r S^{\eta}=0
$$


Define the polynomial

$$
\varphi(\eta)=\frac{1}{2} \sigma^{2} \eta^{2}+\left(\mu-\frac{\sigma^{2}}{2}\right) \eta-r=0
$$

whose roots are

$$
\eta_{0}, \eta_{1}=\frac{1}{2}-\frac{\mu}{\sigma^{2}} \pm \sqrt{\left(\frac{\mu}{\sigma^{2}}-\frac{1}{2}\right)^{2}+\frac{2 r}{\sigma^{2}}},
$$

where $\eta_{0}<0$ and $\eta_{1}>1$.

The particular solution to the differential equation (28) requires special attention. Notice that the profit function (3) is not differentiable at $\widetilde{S}$. We derive a solution to (28) not for all exchange rates but only for those values above $\widetilde{S}$. In the numerical solution to the model, we verify that the exchange rate that makes the exporting firm go multinational is in fact above $\widetilde{S}$. Therefore, while the domestic firm exports, the exchange rate will be higher than $\widetilde{S}$ and the relevant part of the profit function does not include the kink.

An educated guess indicates that a particular solution to (28) is

$$
Y_{0}(S)=a S+b S^{-1}+c
$$

where

$$
\begin{aligned}
& a=-\frac{(1-\tau)\left(\alpha+(N-1) \gamma^{*}\right)^{2}}{\beta(N+1)^{2}(\mu-r)} \\
& b=-\frac{(N \gamma)^{2}}{\beta(N+1)^{2}(1-\tau)\left(\sigma^{2}-\mu-r\right)} \\
& c=-\frac{1}{r}\left(\frac{2\left(\alpha+(N-1) \gamma^{*}\right) N \gamma}{\beta(N+1)^{2}}+\phi\right)
\end{aligned}
$$

Similarly, a particular solution to $(29)$ is

$$
Y_{1}(S)=e S
$$

where

$$
e=\frac{1}{r-\mu}\left[\frac{1}{\beta}\left(\frac{\alpha-\gamma^{*}}{N+1}\right)^{2}-\phi^{*}\right]
$$

The general solution can be written as

$$
\begin{gathered}
V_{0}(S)=A_{0} S^{\eta_{0}}+B_{0} S^{\eta_{1}}+a S+b S^{-1}+c, \\
V_{1}(S)=A_{1} S^{\eta_{0}}+B_{1} S^{\eta_{1}}+e S,
\end{gathered}
$$

where $A_{0}, A_{1}, B_{0}$ and $B_{1}$ are constants to be determined. 
Conventional wisdom says that exporting is profitable when the domestic currency is depreciated. Similarly, buying a foreign firm or setting up a plant abroad is profitable when the domestic currency is appreciated. This simple reasoning places some restrictions on the general solution given above.

As the exchange rate tends to infinity, the option value of investing abroad becomes worthless, so we should impose the restriction that the coefficient $B_{0}$ corresponding to the positive root must be zero, otherwise the value of the firm in state 0 explodes. If the exchange rate tends to zero the option value of exporting tends to zero. Hence, coefficient $A_{1}$ corresponding to the negative root must be zero, otherwise the value of the firm in state 1 explodes. Under these restrictions we can rewrite (33) and (34) as

$$
\begin{gathered}
V_{0}(S)=A S^{\eta_{0}}+a S+b S^{-1}+c, \\
V_{1}(S)=B S^{\eta_{1}}+e S .
\end{gathered}
$$

\section{A.5. Market value of a Foreign firm}

An educated guess indicates that a particular solution to (15) is

$$
Y_{0}^{*}(S)=a^{*}+b^{*} S^{-2}+c^{*} S^{-1},
$$

where

$$
\begin{gathered}
a^{*}=\frac{1}{r}\left(\frac{1}{\beta}\left(\frac{\alpha-2 \beta}{N+1}\right)^{2}-\phi^{*}\right) \\
b^{*}=-\frac{\gamma^{2}}{(\beta(N+1)(1-\tau))^{2}\left(3 \sigma^{2}-2 \mu-r\right)} \\
c^{*}=-\frac{\beta(N+1) \gamma\left(\alpha-\gamma^{*}\right)-\beta\left(N \alpha-(N-1) \gamma^{*}\right) \gamma+\gamma\left(\alpha-2 \gamma^{*}\right)}{\beta^{2}(N+1)^{2}(1-\tau)\left(\sigma^{2}-\mu-r\right)}
\end{gathered}
$$

Similarly, a particular solution to (16) is

$$
Y_{1}^{*}(S)=e^{*}=\frac{1}{r \beta}\left(\left(\frac{\alpha-\gamma^{*}}{N+1}\right)^{2}-\phi^{*}\right) .
$$

The general solution can be written as

$$
V_{0}^{*}(S)=A_{0}^{*} S^{\eta_{0}}+B_{0}^{*} S^{\eta_{1}}+a^{*}+b^{*} S^{-2}+c^{*} S^{-1},
$$

where $A_{0}^{*}, A_{1}^{*}, B_{0}^{*}$ and $B_{1}^{*}$ are constants to be determined. 
As the exchange rate tends to infinity, the probability that the domestic firm will go multinational tends to zero, thus the effect of the option of the domestic firm on the value of the foreign firm must be zero. Therefore, we should restrict $B_{0}^{*}=0$, otherwise the value of the foreign firm tends to infinity. If the exchange rate tends to zero, the domestic firm goes multinational and the probability that the domestic firm will revert to exporting tends to zero, therefore, we should restrict $A_{1}^{*}=0$, otherwise the value of the foreign firm tends to infinity. Under these restrictions, the solution is

$$
\begin{gathered}
V_{0}^{*}(S)=A^{*} S^{\eta_{0}}+a^{*}+b^{*} S^{-2}+c^{*} S^{-1}, \\
V_{1}^{*}(S)=B^{*} S^{\eta_{1}}+e^{*} .
\end{gathered}
$$

\section{A.6. Robustness}

This appendix reports the results obtained for parameter values different from those used in the benchmark case reported in the main text. In all cases we change the value of one parameter keeping the other paramenter at their benchmark values. We have repeated the experiment for every parameter using several values and report here just one case. Figure 11 shows that reducing the intercept of the inverse demand, $\alpha$, increases the size of the dumping region and hysteresis. Figure 12 indicates that increasing the slope of the inverse demand, $\beta$, has similar effects as the size of the dumping region also increases and so does hysteresis. Figures 13 and 14 show that increases in the parameters of the cost function, the marginal cost $\gamma$ and maintenance cost $\phi$, also increase the size of the dumping region but reduce the degree of hysteresis. Figure 15 points out that increases in the entry and exit costs $I$ and $L$ increase the degree of hysteresis but do not affect the dumping-trigger exchange rate, $\widehat{S}$. Finally, figures 16 and 17 show how increases in the depreciating drift $\mu$ and exchange rate volatility $\sigma$ have opposite effects on the degree of hysteresis and do not affect the dumping-trigger rate $\widehat{S}$. 


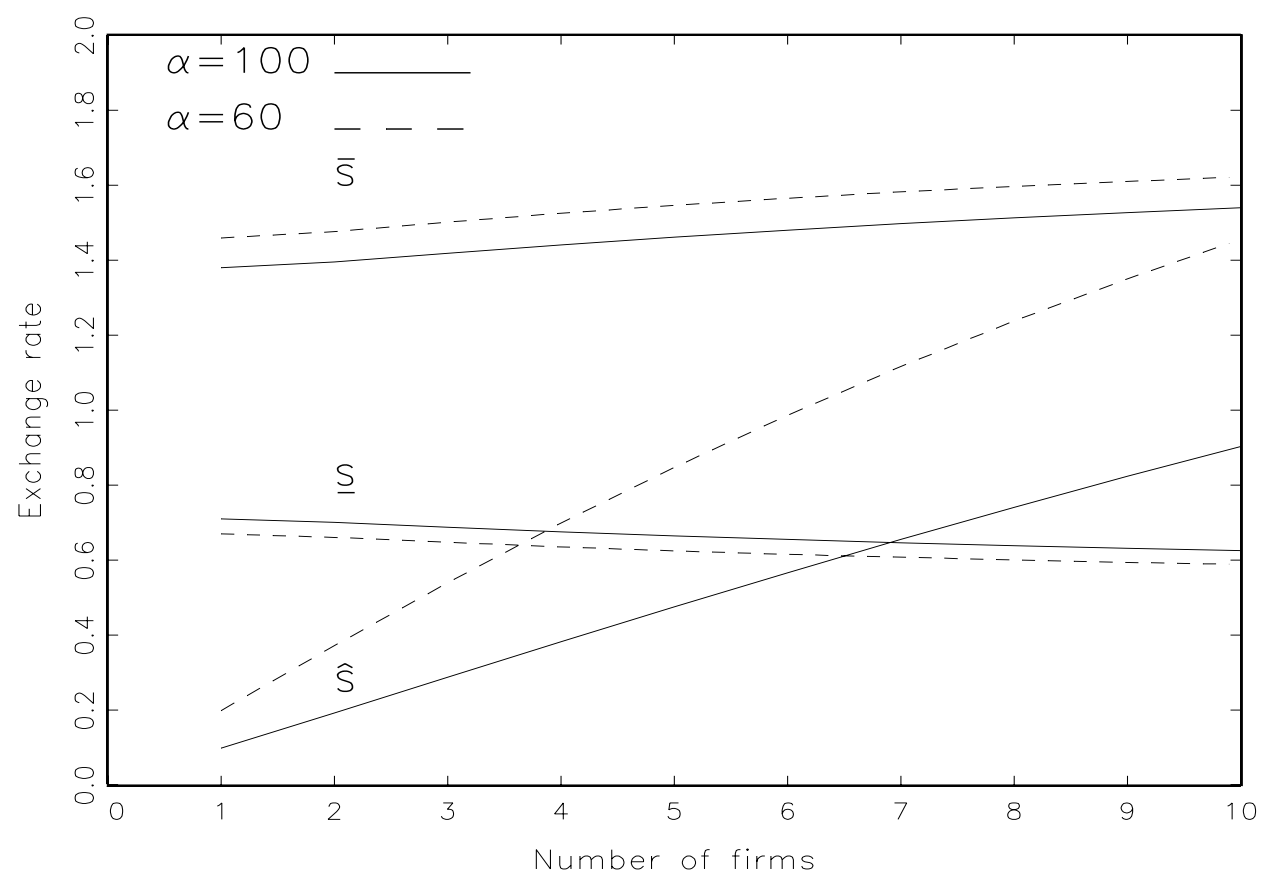

FIGURE 11. This figure shows the trigger exchange rate values and the dumpingtrigger exchange rates for two different values of the intercept of the demand function.

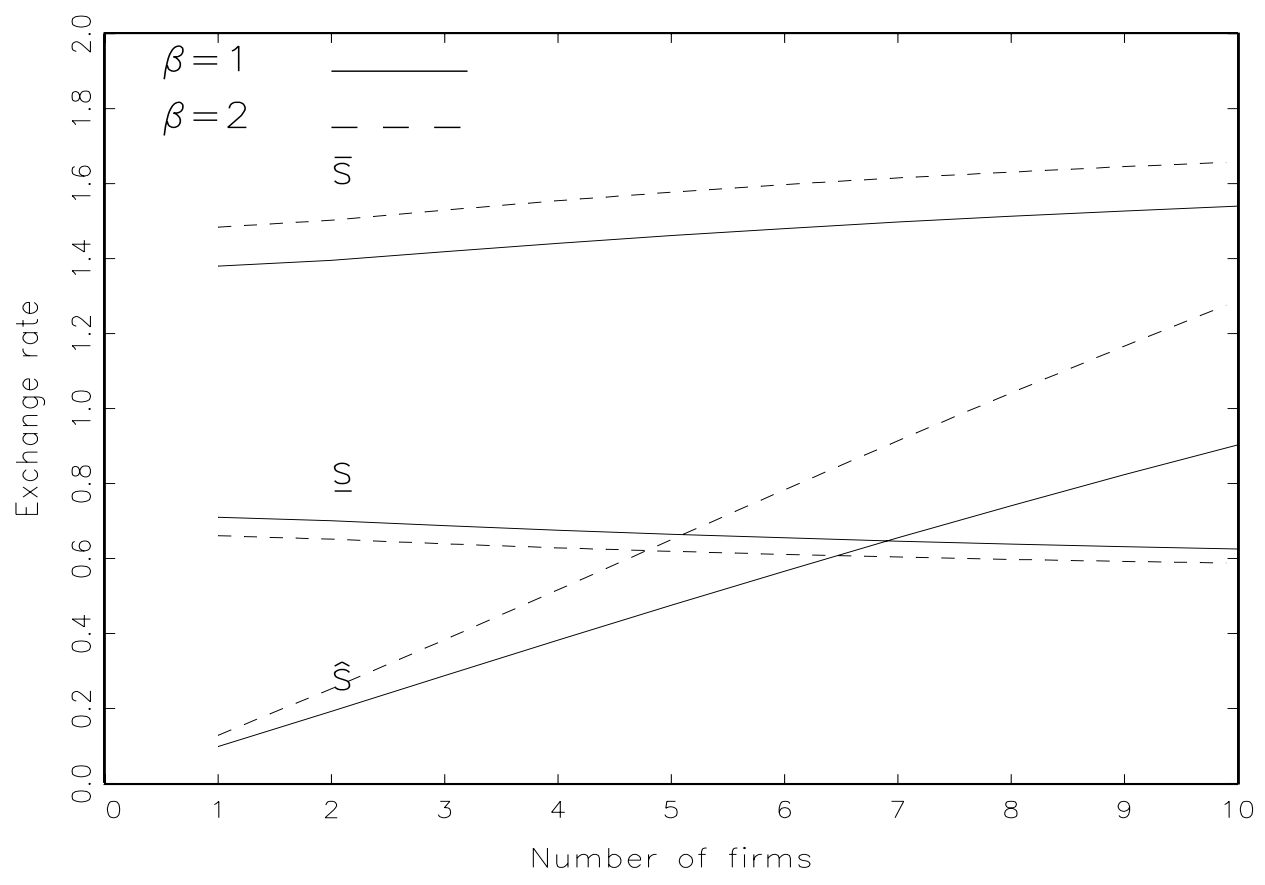

FiguRE 12. This figure shows the trigger exchange rate values and the dumpingtrigger exchange rates for two different values of the slope of the inverse demand function. 


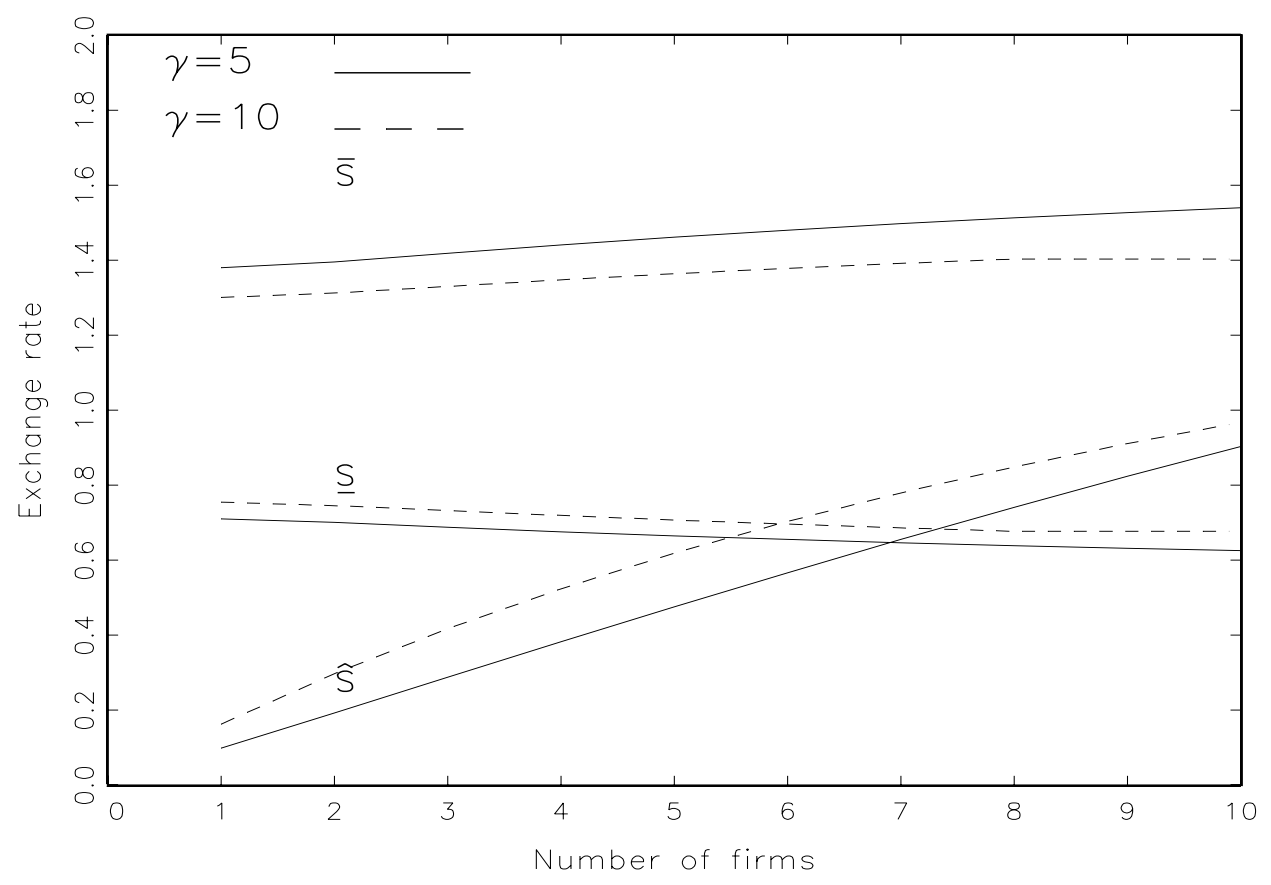

FiguRE 13. This figure shows the trigger exchange rate values and the dumpingtrigger exchange rates for two different values of the marginal cost.

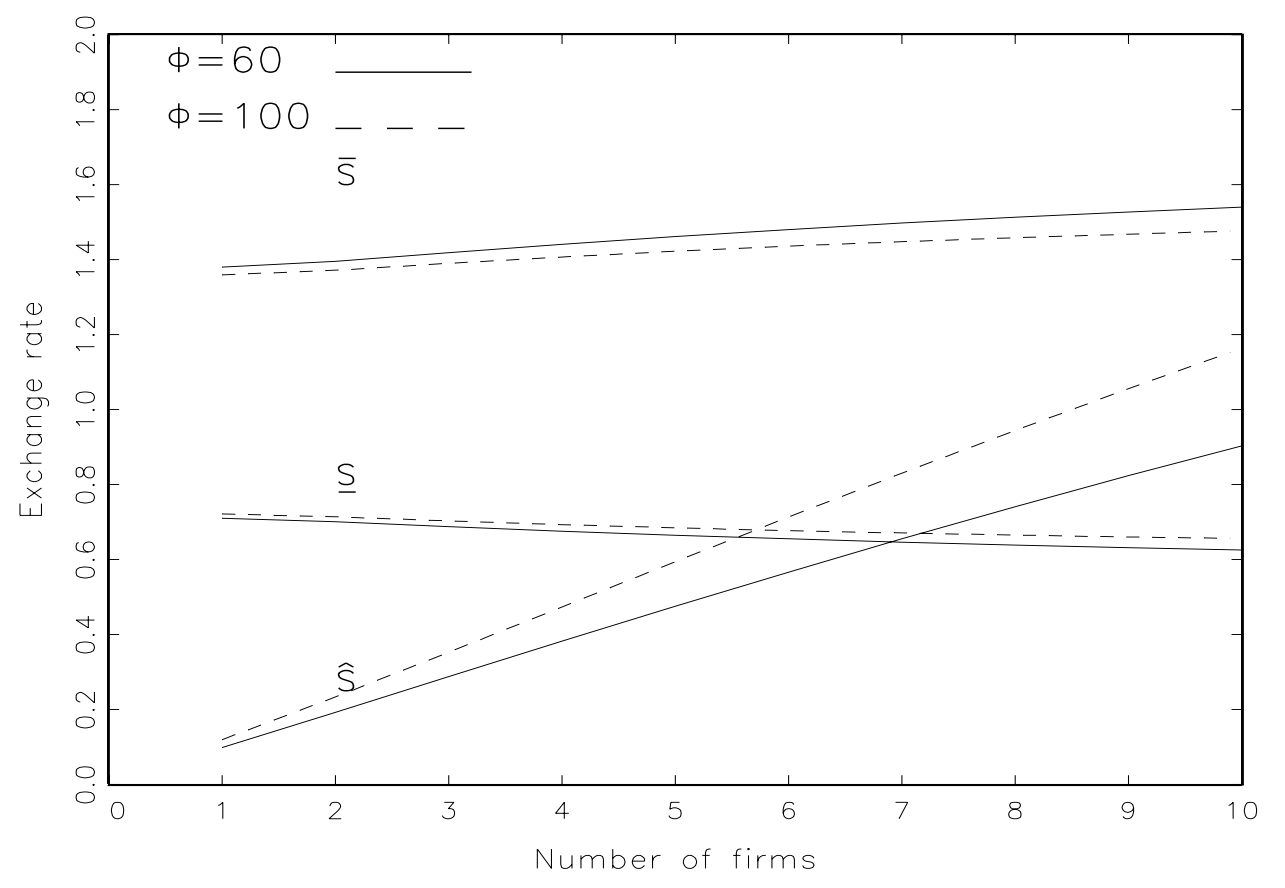

FiguRE 14. This figure shows the trigger exchange rate values and the dumpingtrigger exchange rates for two different values of the maintenance cost. 


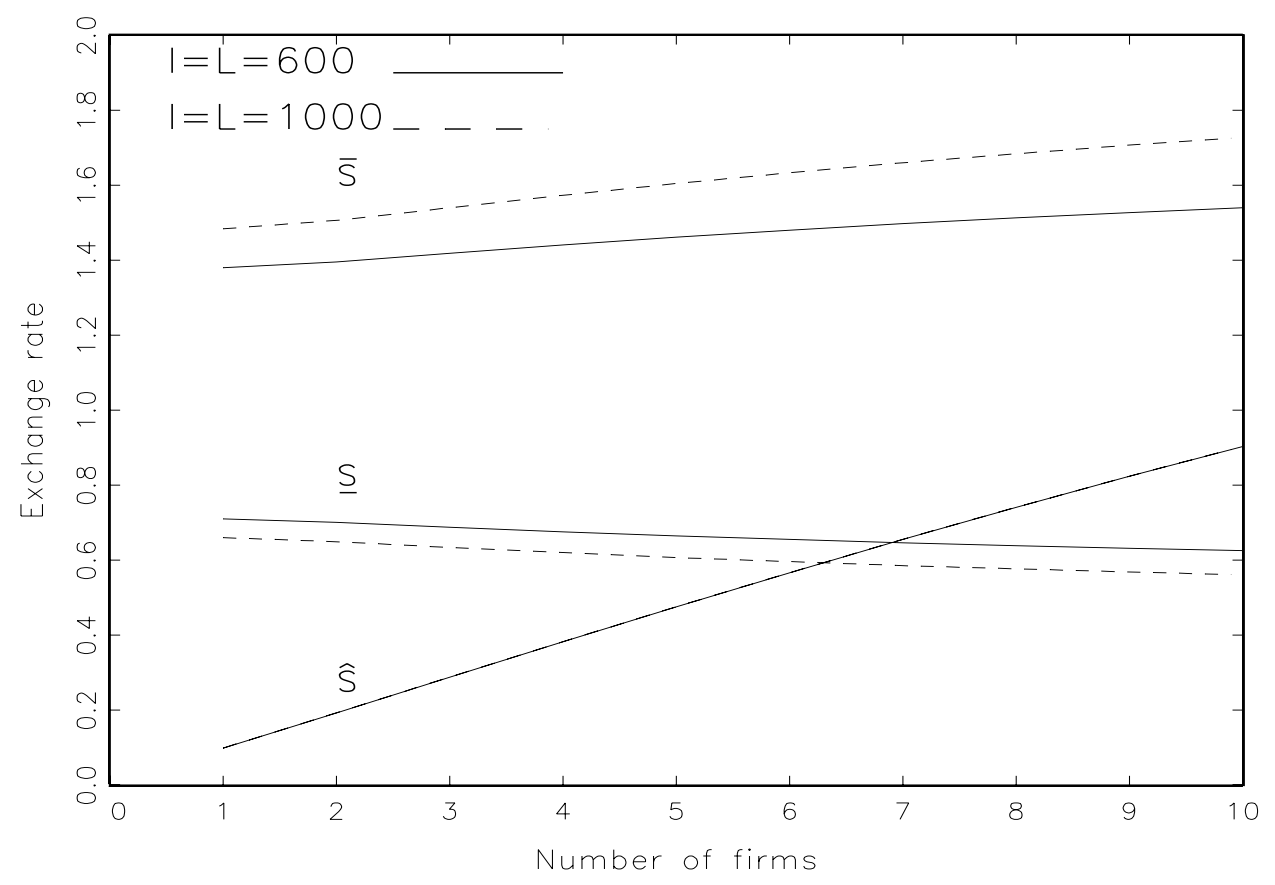

FIGURE 15. This figure shows the trigger exchange rate values and the dumpingtrigger exchange rates for two different values of the entry and exit costs.

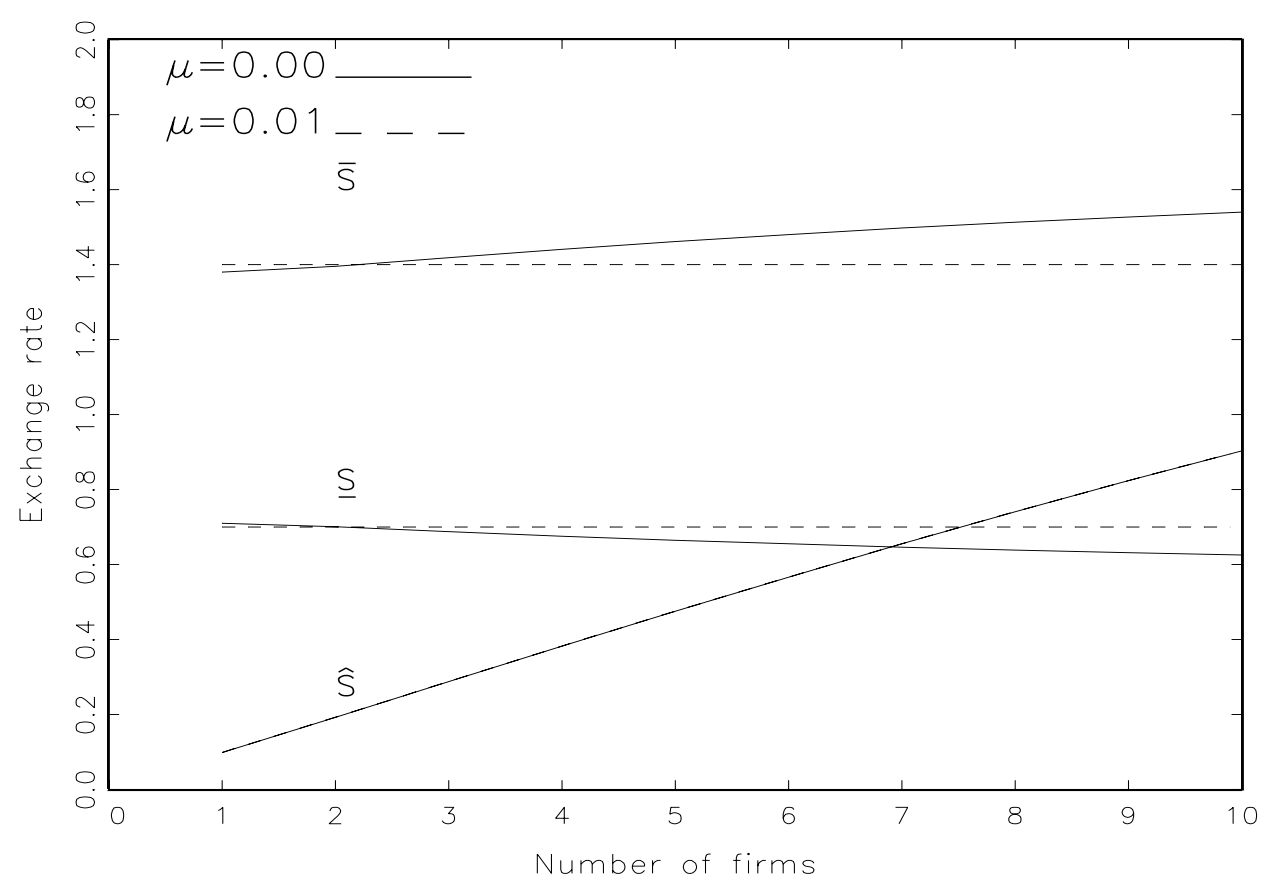

FiguRE 16. This figure shows the trigger exchange rate values and the dumpingtrigger exchange rates for two different values of the depreciation drift. 


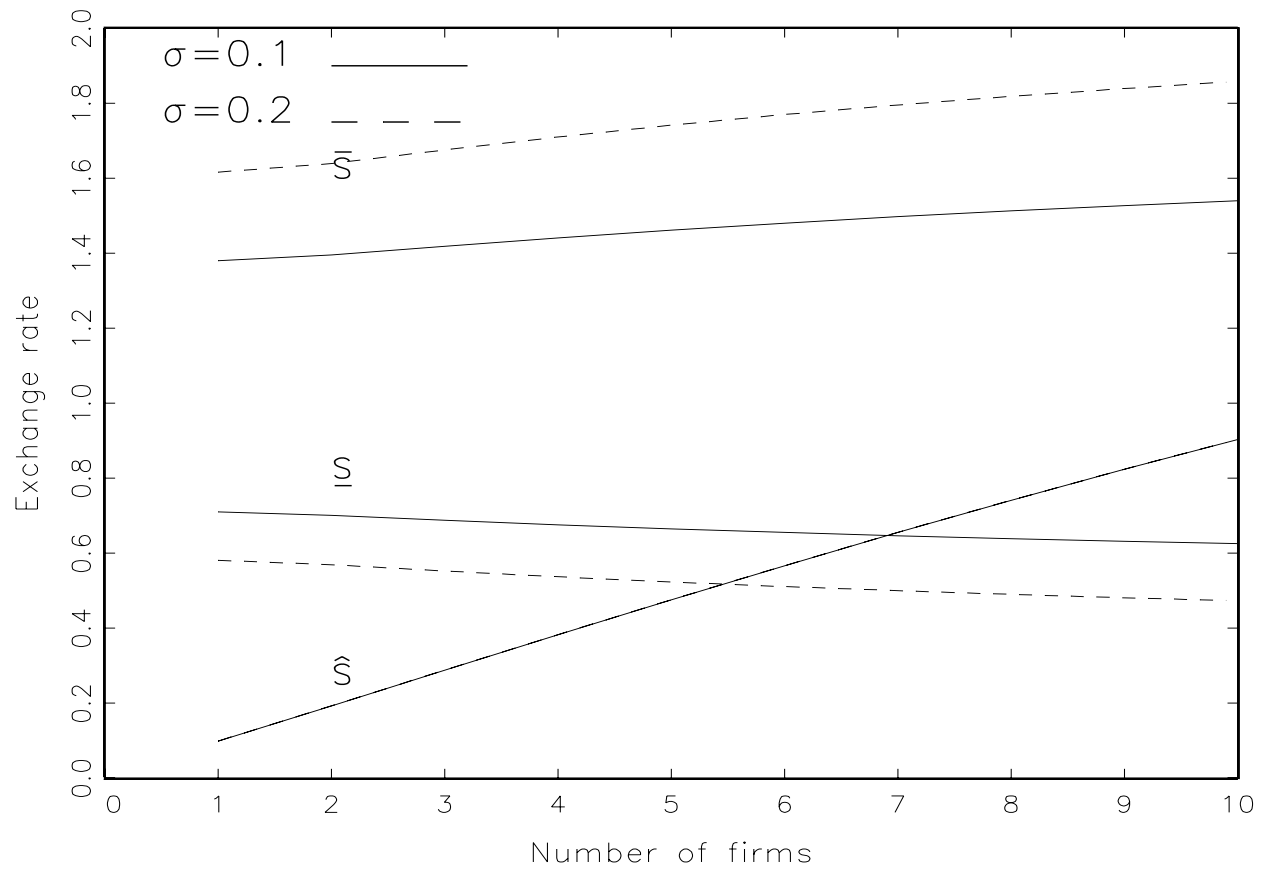

FIGURE 17. This figure shows the trigger exchange rate values and the dumpingtrigger exchange rates for two different values of exchange rate volatility parameter. 


\section{REFERENCES}

[1] Belderbos, R., H. Vandenbussche and R. Veugelers. 2004. Antidumping Duties, Undertakings, and Foreign Direct Investment in the EU. European Economic Review 48, 429-453.

[2] Blonigen, B.A. 1997. Firm-Specific Assets and the Link between Exchange Rates and Foreign Direct Investment. The American Economic Review Vol. 87, (3), 447-465.

[3] Brander, James and Paul Krugman. 1983. A Reciprocal Dumping Model of International Trade. Journal of International Economics 15, 313-321.

[4] Brouwer, J., R. Paap and J.M. Viaene. 2008. The Trade and FDI effects of EMU enlargement. Journal of International Money and Finance 27, 188-208.

[5] Buch, C. M. and J. Kleinert. 2008. Exchange Rates and FDI: Goods versus Capital Market Frictions. World Economy 31, 1185-1207.

[6] Campa, J.M. 1993. Entry by Foreign Firms in the United States under Exchange Rate Uncertainty. Review of Economics and Statistics November 1993, 75(4), 614-22.

[7] Campa, J. M., S. Donnenfeld and S. Weber. 1998. Market Structure and Foreign Direct Investment. Review of International Economics, 6(3), 361-380.

[8] Darby, J., A. H Hallett, J. Ireland and L.Piscitelly. 1999. The Impact of Exchange Rate Uncertainty on The Level of Investment. The Economic Journal 55-67.

[9] Davies, Stephen W. and Anthony J. McGuiness. 1982. Dumping at Less Than Marginal Cost. Journal of International Economics 12, 169-182.

[10] Delgado, F. 1991. Hysteresis, Menu Costs, and Pricing with Random Exchange Rates. Journal of Monetary Economics 28(3), 461-84.

[11] Dixit, A. 1979, A Model of Duopoly Suggesting a Theory of Entry Barriers, Bell Journal of Economics 10(1), 20-32.

[12] Dixit, A.1989a. Entry and Exit Decisions under Uncertainty. Journal of Political Economy Vol 97, (3), 620-638.

[13] Dixit, A.1989b. Hysteresis, Import Penetration and Exchange Rate Pass-Through. Quarterly Journal of Economics. Vol 104,(2), 205-228.

[14] Dixit A. and R.S. Pindyck. 1994. Investment Under Uncertainty. Princeton University Press.

[15] Goldberg, Linda S. and C.D. Kolstad. 1995. Foreign Direct Investment, Exchange Rate Variability and Demand Uncertainty. International Economic Review, Vol 53, (4), (Nov), 855-873.

[16] Gottschalk, S. and S. Hall. 2008. Foreign Direct Investment and Exchange Rate Uncertainty in South-East Asia. International Journal of Finance and Economics 13, 349-359.

[17] Grenadier, S. R. 2002. Option Exercise Games: An Application to the Equilibrium Investment Strategies of Firms. Review of Financial Studies, 15(3), 691-721.

[18] Helpman, E., M. J. Melitz and S. R. Yeaple, 2004. Export Versus FDI With Heterogeneous Firms. American Economic Review, 94(1), 300-316.

[19] Knetter, M. and T. Prusa, 2003. Macroeconomic Factors and Antidumping Filings: Evidence from four countries. Journal of International Economics 61, 1-17.

[20] Kreps, D.M. and Scheinkman, J.A. 1983. Quantity Precommitment and Bertrand Competition yield Cournot Outcomes. The Bell Journal of Economics, 14, no. 2 , 236-337.

[21] Lee, K.H. and J. S. Mah. 2003. Institutional Changes and Antidumping Decisions in the United States. Journal of Policy Modeling 25, 555-565.

[22] Levitan, R. and M. Shubik. 1972. Price Duopoly and Capacity Constraints. International Economic Review, 13, no. 1, 111-122.

[23] McDonald, R. and D. Siegel 1986. The Value of Waiting to Invest. Quarterly Journal of Economics Vol 101 ,(Nov), 707-727.

[24] Motta, M. 1992. Multinational Firms and The Tariff-Jumping Argument. European Economic Review 36, $1557-1571$.

[25] Moreno, D. and L. Ubeda. 2006. Capacity Precommitment and Price Competition yield the Cournot Outcome. Games and Economic Behavior, 56, 323-332.

[26] Nelson, D. 2006, The political economy of antidumping: A survey. European Journal of Political Economy $22,3,554-590$.

[27] Novy-Marx, R. 2007, An Equilibrium Model of Investment Under Uncertainty Review of Financial Studies 20, 1461-1502. 
[28] Paxson, D. and H. Pinto 2005, Rivalry under Price and Quantity Uncertainty. Review of Financial Economics 14, 209-224.

[29] Poddar, S. and D. Sasaki. 2002. The Strategic Benefit from Advance Production. European Journal of Political Economy, 18, 579-595.

[30] Rob R. and N. Vettas 2003. Foreign Direct Investment and Exports with Growing Demand. The Review of Economic Studies, 70, no. 3, 629-648.

[31] Rotemberg, J.J. and G. Saloner. 1989. The Cyclical Behavior of Strategic Inventories. The Quarterly Journal of Economics, 104, no. 1, 73-97.

[32] Russ, K. N. 2007. The Endogeneity of the Exchange Rate as a Determinant of FDI: A Model of Entry and Multinational Firms. Journal of International Economics 71, 344-372.

[33] Shrikhande, M. M. 2002. A General Equilibrium Analysis of Foreign Direct Investment and the Real Exchange Rate International Journal of Finance and Economics 7, 309-325.

[34] Smit, H. T. J. and L. Trigeorgis. 2004. Strategic Investment: Real Option Games. Princeton University Press.

[35] Sercu, P. and C. Vanhulle 1992, Exchange Rate Volatility, International Trade, and the Value of Exporting Firms, Journal of Banking and Finance 16, 155-182.

[36] Sung, H. and H.A. Lapan. 2000. Strategic Foreign Direct Investment and Exchange Rate Uncertainty. International Economic Review Vol 41, (2), (May), 411-423.

[37] Thille, H. 2006. Inventories, market structure, and price volatility. Journal of Economic Dynamics and Control 30, 1081-1104.

[38] Trigeorgis, L. 1996. Real Options. The MIT Press, Cambridge, Massachusetts.

[39] Xing, Y. and G. Wan. 2006. Exchange Rates and Competition for FDI in Asia, World Economy 29, 419-434.

[40] Xing, Y. 2006. Why is China so Attractive for FDI? The Role of Exchange Rates. China Economic Review $17,198-209$.

[41] Wong, Kar-yiu. 1995. International Trade in Goods and Factor Mobility. The MIT Press. 